\title{
Multi-physics and Multi-Scale Benchmarking and Uncertainty Quantification within OECD/NEA Framework
}

\author{
M. Avramova ${ }^{1}$, K. Ivanov ${ }^{1}$, T. Kozlowski ${ }^{2}$, I. Pasichnyk ${ }^{3}$, W. Zwermann ${ }^{3}$, K. Velkov ${ }^{3}$, \\ E. Royer ${ }^{4}$, A. Yamaji ${ }^{5}$, J. Gulliford ${ }^{5}$ \\ 1 - The Pennsylvania State University (PSU), USA \\ 2 - University of Illinois at Urbana-Champaign, USA \\ 3 - Gesellschaft für Anlagen- und Reaktorsicherheit (GRS) mbH, Germany \\ 4 - INSTN - CEA Saclay, France \\ 5 - OECD/NEA, France
}

\begin{abstract}
The development of multi-physics multi-scale coupled methodologies for Light Water Reactor (LWR) analysis requires comprehensive validation and verification procedures, which include well-established benchmarks developed in international cooperation. The Nuclear Energy Agency (NEA) of the Organization for Economic Co-operation and Development (OECD) has provided such framework, and over the years a number of LWR benchmarks have been developed and successfully conducted. The first set of NEA/OECD benchmarks that permits testing of the neutronics/thermal-hydraulics coupling, and verifying the capability of the coupled codes to analyze complex transients with coupled core/plant interactions have been completed and documented. These benchmarks provided a validation basis for the new generation of coupled "best-estimate" codes. The above mentioned OECD/NEA LWR benchmark activities have also stimulated follow up developments and benchmarks to test these developments. The models utilized have been improved when moving from one benchmark to the next and this created a need to validate them using high-quality experimental data. Second set of the NEA/OECD benchmarks have been initiated by the Expert Group on Uncertainty Analysis in Modelling (EGUAM) at the Nuclear Science Committee (NSC), NEA/OECD to address the current trends in the development of LWR multiphysics and multi-scale modeling and simulation. These benchmarks include the following common features, which address some of the issues identified in the first set of OECD/NEA benchmarks: a) utilization of high-quality experimental data; b) refined local scale modeling in addition to global predictions; c) more detailed comparisons and analysis; d) including uncertainty and sensitivity analysis of modeling predictions. The paper presents each of these new benchmarks by providing description and discussion of comparative analysis of obtained results. Special attention is devoted to uncertainty propagation in LWR multi-physics and multi-scale simulations for design and safety evaluations.
\end{abstract}

Key Words: Benchmark, Uncertainty, Multi-physics, Multi-scale

\section{Introduction}

The development of multi-physics multi-scale coupled methodologies for Light Water Reactor (LWR) analysis requires comprehensive validation and verification procedures, which include well-established benchmarks developed in international cooperation. The Nuclear Energy Agency (NEA) of the Organization for Economic Co-operation and Development (OECD) has provided such framework, and over the years a number of LWR benchmarks have been developed and successfully conducted. The first set of NEA/OECD benchmarks that permits testing of the neutronics/thermal-hydraulics coupling, and verifying the capability of the coupled codes to analyze complex transients with coupled core/plant interactions have been summarized in Ref. [1]. Such benchmarks are the OECD/ US Nuclear Regulatory Commission (NRC) Pressurized Water Reactor (PWR) Main Steam Line Break (MSLB) benchmark, the OECD/NRC Boiling Water Reactor (BWR) Turbine Trip (TT) benchmark, and the OECD/US

\footnotetext{
* Corresponding author - e-mail: mna109@psu.edu; Tel.: +1-814-865-0043; Fax: +1-814-865-8499
} 
Department of Energy (DOE)/CEA VVER-1000 Coolant Transient (V1000CT) benchmark. These benchmarks provide a validation basis for the current generation of coupled neutronics/thermal-hydraulics best-estimate codes

The above mentioned OECD/NEA LWR benchmark activities have also stimulated follow up developments and benchmarks to test new developments. The models utilized have been improved when moving from one benchmark to the next and this created a need to validate these refined models using high-quality experimental data. Second set of OECD/NEA benchmarks have been initiated by the Expert Group on Uncertainty Analysis in Modelling (EGUAM) at the Nuclear Science Committee (NSC) to address the current trends in the development of LWR multi-physics and multi-scale modeling and simulation as well as some of the issues identified in the first set of OECD/NEA benchmarks. Especially important trends are extending analysis capabilities by coupling models, which simulate different phenomena; refining the scale of multi-physics coupling (high-fidelity calculations); and incorporation of uncertainty and sensitivity analysis in reactor simulations. The major task of the EGUAM is to address verification, validation and uncertainty analysis of multi-scale and multi-physics modeling and simulation. EGUAM has created a roadmap along with schedule and organization for the development and validation of methods and codes required for uncertainty analysis, including the benchmarks adequate to meet those goals.

The paper discusses each of these new benchmarks by providing background and objectives, description and discussion of comparative analysis of obtained results. The following benchmark activities are summarized: OECD/NRC BFBT benchmark, OECD/NRC PSBT benchmark, OECD/NRC Oskarshamn-2 BWR Stability benchmark, OECD Kalinin-3 VVER-1000 Coupled Code benchmark, and OECD UAMLWR benchmark. Special attention is devoted to uncertainty propagation in LWR multi-physics and multi-scale simulations for design and safety evaluations.

Since the concept of benchmarks are used throughout this paper, its meaning for the discussed OECD/NEA benchmarks is defined. Achieving the next level of credibility in computational simulations of nuclear reactor design and safety requires concerted and determined efforts. The goal of these efforts is to improve the reliability of the computer software, the estimation of numerical accuracy, the quality of the physics models used, and the quantification of uncertainty (Oberkampf and Trucano, 2008). This paper focuses on one aspect of the needed improvements to software reliability and physics modeling, namely, the construction and use of highly demanding Verification \& Validation (V\&V) benchmarks. The discussed in this paper OECD/NEA benchmarks of interest are those related to the accuracy and reliability of physics models and codes. These benchmarks are combination of verification and validation benchmark exercises which involve both use of experimental (measured) data and reference solutions i.e. code-to-data and code-to-code comparisons. When comparing code predictions to experimental data in these benchmarks usually the experimental uncertainties are provided.

It should be noted that while the Kalinin-3, Oskarshamn-2 and UAM-LWR are multi-physics benchmarks, the BFBT and PSBT benchmarks are thermal-hydraulics multi-scale benchmarks, which are related to coupled multi-physics analyses. The reason is that the core thermal-hydraulic models, which are being tested in BFBT and PSBT benchmarks, are providing moderator feedback in multi-physics simulations. The importance of correct prediction of global and local moderator feedback was shown in the first set of the OECD/NEA benchmarks such as PWR MSLB, BWR TT and V1000CT benchmarks.

All of the benchmarks of the second set of OECD/NEA benchmarks incorporated uncertainty and sensitivity analysis. The Oskarshamn-2 and UAM-LWR benchmarks are still on-going and for them only selected solutions are presented for benchmark phase/exercises which remain under progress. For such benchmarks, no definitive conclusions would be drawn from the presented limited number of solutions

* Corresponding author - e-mail: mna109@psu.edu; Tel.: +1-814-865-0043; Fax: +1-814-865-8499 
and that these are only given for illustrative purposes, before a wider span of solutions are collected and evaluated.

\section{OECD/NRC BFBT Benchmark}

\subsection{Objectives}

The OECD/NRC Full Size Fine Mesh Bundle Test (BFBT) Benchmark provides high resolution and fullscale experimental data under actual operating conditions to be used for validation of the current models for void distribution and critical power in Boiling Water Reactors (BWR) [2]. This international benchmark has encouraged advancement in the field of two-phase flow theory with very important relevance to the nuclear reactors safety margins evaluation. The BFBT database was developed by the Nuclear Power Engineering Corporation (NUPEC) in Japan and is identified to be one of the most valuable databases for development and assessment of new thermal-hydraulics modeling methodologies.

From 1987 to 1995, NUPEC performed a series of void measurement tests using full-size mock-up tests for both BWRs and pressurized water reactors (PWRs). Based on a state-of-the-art computer tomography (CT) technology, the void distribution was visualized at the mesh size smaller than the sub-channel under actual plant conditions. NUPEC also performed steady-state and transient critical power test series based on the equivalent full-size mock-ups. Considering the reliability not only of the measured data, but also other relevant parameters such as the system pressure, inlet sub-cooling and rod surface temperature, these test series supplied the first substantial database for the development of truly mechanistic and consistent models for void distribution and boiling transition on a sub-channel basis. It should be recognized that the purpose of this benchmark is not only the comparison of currently available computational approaches but above-all the encouragement to develop novel next-generation approaches that focus on more microscopic processes. In this context, the sub-channel grade void fraction data are regarded as the macroscopic data and the digitized computer graphic images are the microscopic data, which provides the detailed void distribution within the sub-channel.

The Pennsylvania State University (PSU) under the sponsorship of NRC has prepared, organized, conducted and summarized the OECD/NRC Benchmark based on NUPEC BWR Full-size Fine-mesh Bundle Tests (BFBT). The international benchmark activities have been conducted in cooperation with the NEA, OECD and Japan Nuclear Energy Safety (JNES) organization, Japan. The JNES has made available the BWR NUPEC database for the purposes of the OECD/NRC BFBT international benchmark. The project was supported by the Japanese Ministry of Economy, Trade and Industry (METI), the US NRC, and is endorsed by the OECD/NEA/NSC. The benchmark team was formed at PSU in collaboration with JNES, and the Commissariat á l'Energie Atomique (CEA), Saclay, France. The BFBT benchmark activity has been very successful with many organizations from different countries participating in benchmark exercises by using subchannel, Computational Fluid Dynamics (CFD) and system thermalhydraulic codes.

\subsection{Summary of results}

The OECD/NRC BFBT benchmark consists of two phases: Phase I (void distribution) and Phase II (critical power) [2].

\subsubsection{Phase I - void distribution benchmark}

The Phase I of the BFBT benchmark (void distribution benchmark) provides data for validation of analytical models of void distribution over a wide range of geometrical and operating conditions. The Phase I includes four exercises. Exercise I-1 is a steady-state sub-channel grade benchmark, where sub-

\footnotetext{
* Corresponding author - e-mail: mna109@psu.edu; Tel.: +1-814-865-0043; Fax: +1-814-865-8499
} 
channel, meso- and microscopic approaches can be used. Exercise I-2 is a steady-state microscopic grade benchmark, which can utilize meso- and microscopic approaches. Exercise I-3 is a transient macroscopic grade benchmark, where a sub-channel approach can be applied. Exercise I-4 is a benchmark on uncertainty analysis of the void distribution prediction [2].

Statistical methodologies have been applied for analysis of code-to-data and code-to-code comparisons of results obtained from the participants for different benchmark exercises. Table 1 lists the participating organizations in Phase I. The BFBT benchmark team adopted a special approach when analyzing the subchannel data. Taking into account the different assembly geometries and power distribution effects, the sub-channels within a fuel bundle were grouped into sub-channel types. Each sub-channel type in a particular assembly is indicated with an ID number. Table 2 and Figure 1 show the sub-channel IDs of assembly type 01 . Assembly type 01 is characterized with two water rods and uniform radial and axial power distributions. Two types of void distribution comparisons, based on a sub-channel level, were performed. The purpose of the adopted comparative analysis was to achieve an objective sense of the participants' accuracy relative to the reference data.

The first type of analysis included void fraction comparison versus channel ID per test case. Exercise 1 of Phase I (Exercise I-1) included fifteen test cases or three cases per assembly type. Each test case is characterized with a different fuel bundle exit quality. This type of comparison is illustrated in Figure 2 for test case 0011-55. The steady-state test conditions are as follows: pressure (7.18 MPa), flow (54 t/h), inlet subcooling $(52.6 \mathrm{~kJ} / \mathrm{kg})$, power of bundle $(1.8 \mathrm{MW})$, and exit quality $(5 \%)$. The experimental data per channel is given with a black triangle (please note that there are several repeating measurements per test), while the participants' results are shown with different colors and shapes. Participants' void fractions were averaged for identical sub-channel type while the reference data were given for each subchannel ID.

Table 1. List of participants in Exercise 1 of Phase I of the BFBT benchmark

\begin{tabular}{|c|c|c|c|c|}
\hline Participant & Abbreviation & Country & Code & Code Type \\
\hline $\begin{array}{c}\text { Korea Atomic Energy } \\
\text { Institute }\end{array}$ & KAERI & Korea & MARS/MATRA & Subchannel \\
\hline $\begin{array}{c}\text { Westinghouse } \\
\begin{array}{c}\text { Royal Institute of } \\
\text { Technology }\end{array}\end{array}$ & Westinghouse & Sweden & MONA 3 & Subchannel \\
\hline $\begin{array}{c}\text { Forschungszentrum } \\
\text { Karlsruhe, Institute for } \\
\text { Reactor Safety }\end{array}$ & FZK & Sweden & TRACE & System \\
\hline $\begin{array}{c}\text { Commissariat à } \\
\text { l'Énergie Atomique }\end{array}$ & CEA & France & NEPTUNE & Subchannel/System \\
\hline $\begin{array}{c}\text { Nuclear Power } \\
\text { Engineering } \\
\text { Corporation }\end{array}$ & NUPEC & Japan & CAPE & Subchannel \\
\hline $\begin{array}{c}\text { AREVA NP GmbH } \\
\text { MREdia }\end{array}$ & AREVA & Germany & F-COBRA-TF/IVA & $\begin{array}{c}\text { Subchannel/Porous } \\
\text { Media }\end{array}$ \\
\hline $\begin{array}{c}\text { The Pennsylvania } \\
\text { State University }\end{array}$ & PSU & USA & COBRA-TF & Subchannel \\
\hline $\begin{array}{c}\text { TEPCO System } \\
\text { Corporation }\end{array}$ & TEPCO & Japan & NASCA & Subchannel \\
\hline $\begin{array}{c}\text { Argonne National } \\
\text { Laboratory }\end{array}$ & ANL & USA & STAR_CD & CFD \\
\hline University of Pisa & UNIPI & Italy & RELAP-3D & System \\
\hline
\end{tabular}

* Corresponding author - e-mail: mna109@psu.edu; Tel.: +1-814-865-0043; Fax: +1-814-865-8499 


\begin{tabular}{|c|c|c|c|c|}
\hline $\begin{array}{c}\text { Universidad } \\
\text { Politécnica de Madrid }\end{array}$ & UPM & Spain & COBRA_TF & Subchannel \\
\hline
\end{tabular}

Table 2. Assembly Type 01 sub-channel types

\begin{tabular}{|l|l|}
\hline ID & Sub-channel Type \\
\hline 1 & Central sub-channel \\
\hline 2 & Internal sub-channel with water rod \\
\hline 3 & Internal sub-channel connected to internal with water rod \\
\hline 4 & Internal sub-channel connected to internal sub-channel \\
\hline 5 & Internal sub-channel connected to side sub-channel \\
\hline 6 & Internal sub-channel connected to two side sub-channels \\
\hline 7 & Side sub-channel connected to corner sub-channel \\
\hline 8 & Side sub-channel \\
\hline 9 & Corner sub-channel \\
\hline
\end{tabular}

The second type of void distribution comparison that was performed is predicted versus measured void fraction per ID and type of assembly. This type of comparison is shown in Figure 3 for the three cases per assembly type. The participants' results are given with different colors and shapes. Standard deviations based on void fraction in a sub-channel and assembly types as well as standard deviations based on bundle average void fraction were summarized. In addition, the performance of the different turbulent mixing and void drift models were compared.

The following conclusions can be made based on submitted results, which constitute "lessons learned" in void fraction calculations and predictions. In general, the scatter in code predictions was less for higher void fractions (greater than $70 \%$ - annular flow). Most scatter in calculations was observed for lower void fractions - bubbly to large bubble/slugging flow void fraction range (void fraction less than $40 \%$ ), but the scatter was still significant in churn-turbulent void fraction range (approximately 40\%). In most of the cases, the porous media codes stay in the lower bound of the predicted void fractions, while the system codes stayed within the upper bound. Most of the codes failed to predict the void distribution near water rods, especially for the low-voided cases. Comparing the performance of the cross-flow models, it can be concluded that the mixing length approach gives the best prediction of the measured data (besides the user effect that can be clearly seen in some results). The porous media approach (including CFD predictions) generally underestimated the void fraction.

* Corresponding author - e-mail: mna109@psu.edu; Tel.: +1-814-865-0043; Fax: +1-814-865-8499 


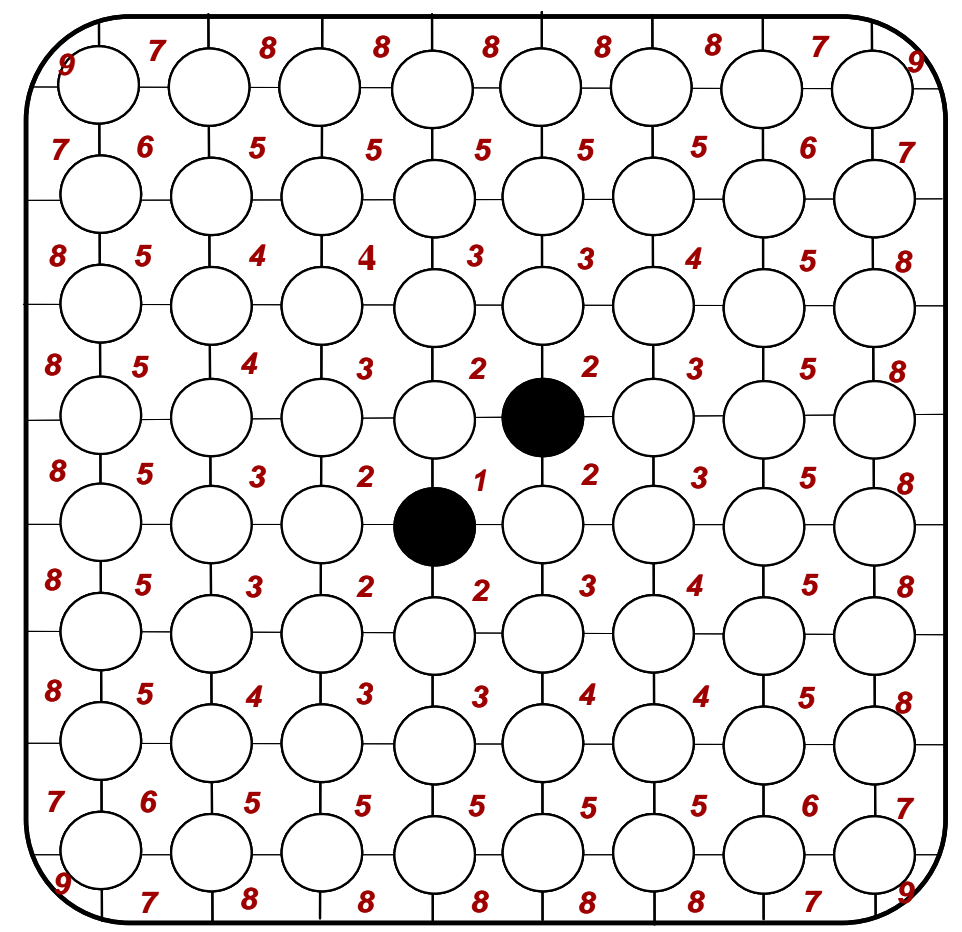

Figure 1. Assembly Type 01 - sub-channel types

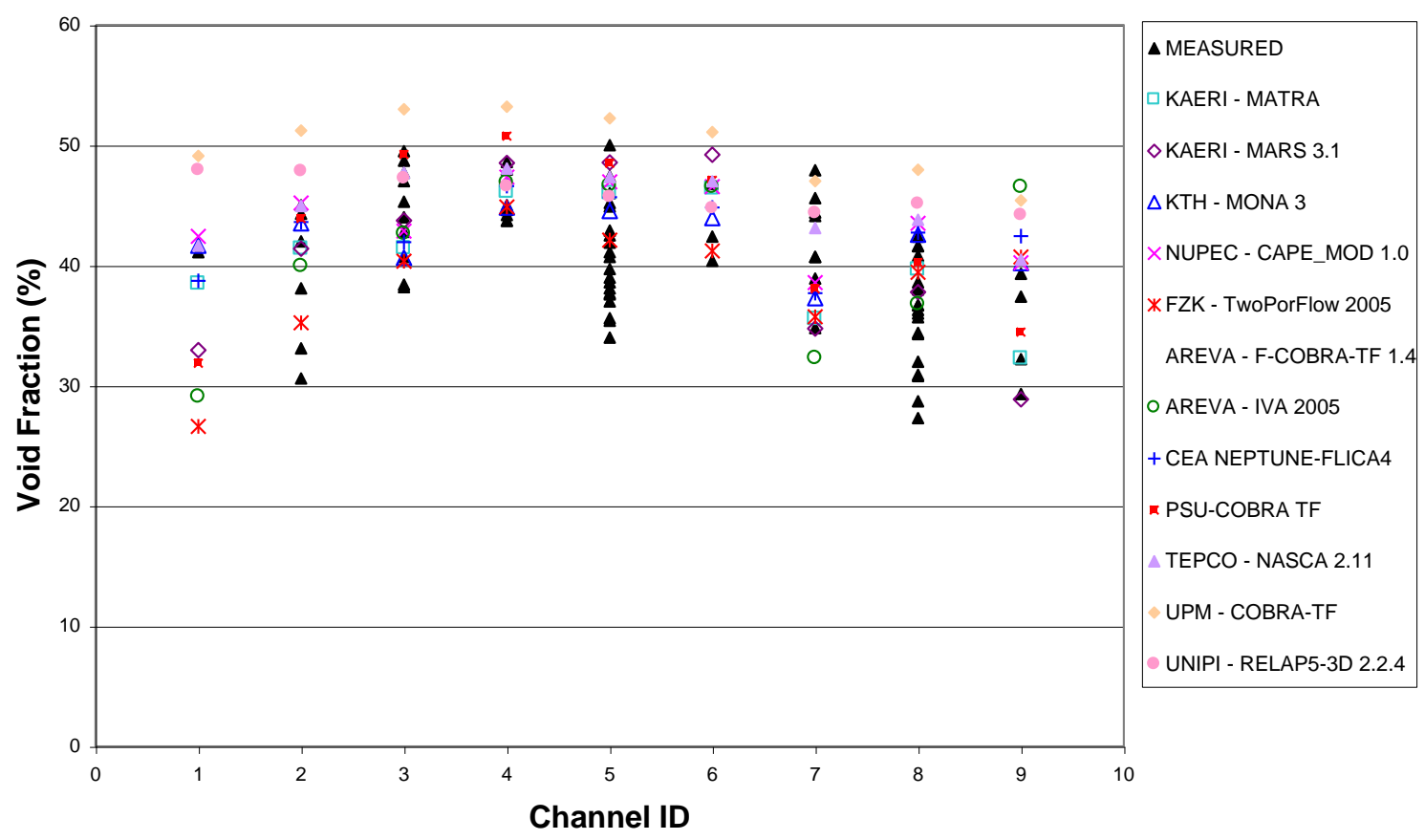

Figure 2. Sub-channel void distribution results for test case 0011-55

* Corresponding author - e-mail: mna109@psu.edu; Tel.: +1-814-865-0043; Fax: +1-814-865-8499 


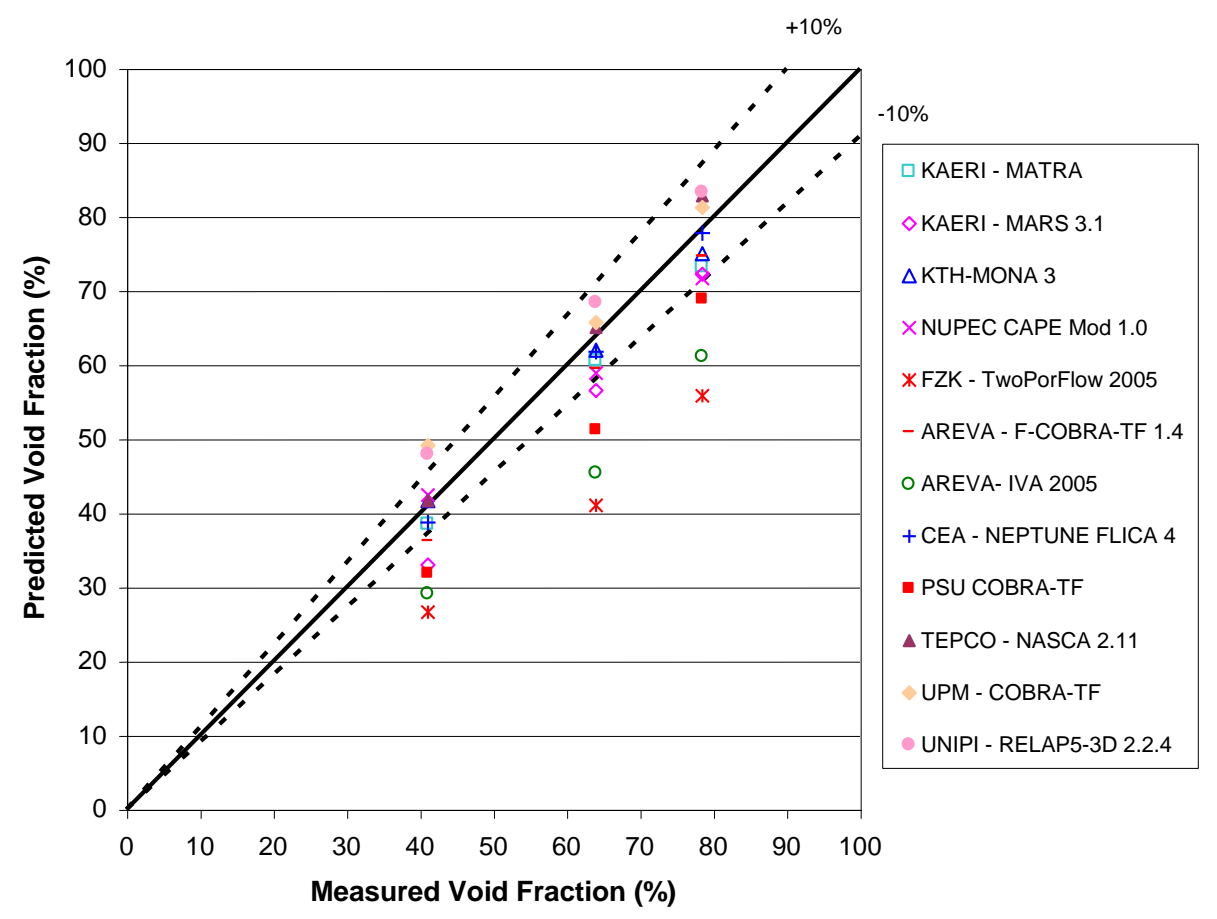

Figure 3. P/M void distribution results based on assembly type 01 and sub-channel type 1 - central channel

Exercise I-2 is a steady state microscopic grade benchmark and was calculated by CFD codes. Four test cases (the test conditions are given in Table 3) were considered in this exercise, characterized with different exit quality and based on high burn-up fuel bundle design with one water rod, uniform axial power profile and particular radial power distribution. The comparative analysis in Exercise 2 of Phase I included quantitative comparison where the CT scanner sub-channel average void fraction, as given in the BFBT data, was utilized. The data were used to calculate the measured bundle average void fraction with and without area weighting - see Tables $4 \mathrm{a}$ and $4 \mathrm{~b}$.

Table 3. Extracted Processed Conditions Chosen for the Particular Exercise Case - Steady-State Void Distribution Measurements

\begin{tabular}{|c|c|c|c|c|c|c|}
\hline Test No. & $\begin{array}{c}\text { Assembly } \\
\text { type }\end{array}$ & $\begin{array}{c}\text { Pressure } \\
(\mathrm{MPa})\end{array}$ & $\begin{array}{c}\text { Flow } \\
\text { rate } \\
(\mathrm{t} / \mathrm{h})\end{array}$ & $\begin{array}{c}\text { Inlet sub- } \\
\text { cooling } \\
(\mathrm{kJ} / \mathrm{kg})\end{array}$ & $\begin{array}{c}\text { Power } \\
(\mathrm{MW})\end{array}$ & $\begin{array}{c}\text { Exit } \\
\text { quality } \\
(\%)\end{array}$ \\
\hline $4101-53$ & 4 & 7.159 & 55 & 50.2 & 2 & 1.24 \\
\hline $4101-55$ & 4 & 7.20 & 54.6 & 52.9 & 1.92 & 5.0 \\
\hline $4101-58$ & 4 & 7.15 & 54.6 & 50.6 & 3.52 & 12.1 \\
\hline $4101-61$ & 4 & 7.18 & 54.7 & 52.5 & 6.48 & 25.1 \\
\hline
\end{tabular}

Table 4a. Sub-channel average void fraction with area weighting

\begin{tabular}{|c|c|c|c|}
\hline Test Number & MEASURED & CFX 10.0 (KAERI) & STAR-CD 3.26 (ANL) \\
\hline $4101-53$ & 26.24 & 25.50 & - \\
\hline $4101-55$ & 41.61 & - & 38.34 \\
\hline $4101-58$ & 60.80 & - & 59.59 \\
\hline
\end{tabular}

* Corresponding author - e-mail: mna109@psu.edu; Tel.: +1-814-865-0043; Fax: +1-814-865-8499 
STAR-CD 3.26 (ANL) results were submitted for all requested cases except for test case 4101-53. Visual comparison of STAR-CD 3.26 (ANL) results with measured CT pixel void fraction data is shown in Figure 4 for test case 4101-55. STAR-CD 3.26 demonstrates significant improvement in predicting the in-channel void distribution. The code shows very good agreement with the experimental data for both bundle-average and detailed in-channel void distributions. The reason that ANL with STAR-CD is the most successful participant in the prediction of void distribution within a BWR fuel assembly is model improvement in the STAR-CD, which includes a special BWR module called Extended Boiling Framework. The Extended Boiling Framework uses an inter-phase surface topology map. It determines the local configuration of vapor and liquid as a function of flow conditions and prescribes which models and properties are relevant for each computational cell. It includes, in addition to the bubbly topology, a droplet or mist topology and a transition topology. The droplet topology consists of liquid droplets flowing in a continuous vapor stream. The ensemble of many computational cells with relatively simple inter-phase surface topologies can provide complex global topologies that include all the traditional flow regimes. The other model improvements in STAR-CD Model improvements in the STAR-CD include the second generation boiling model which extends the treatment of the inter-phase forces to cover the spectrum of flow topologies expected in a BWR fuel assembly. The drag force models, for example, cover bubbles in the sub-cooled or saturated bubbly flow topology, a mixture of Taylor bubbles and smaller bubbles in the slug-flow transition topology, and droplets in the droplet or mist topology. The inter-phase forces considered in the model include drag, turbulent drag, virtual mass, lift, and wall lubrication forces. In addition, inter-phase momentum transfer associated with mass transfer is considered.

Table 4b. Sub-channel average void fraction without area weighting

\begin{tabular}{|c|c|c|c|c|c|}
\hline $\begin{array}{c}\text { Test } \\
\text { Number }\end{array}$ & MEASURED & CFX 10.0 (KAERI) & $\begin{array}{c}\text { NEPTUNE_CFD } \\
1.0 .6 \text { (UNIPI) }\end{array}$ & $\begin{array}{c}\text { FLUENT 6.4 } \\
(\text { HU) }\end{array}$ & $\begin{array}{c}\text { STAR-CD 3.26 } \\
\text { (ANL) }\end{array}$ \\
\hline $4101-53$ & 21.96 & 26.79 & 31.80 & 19.97 & - \\
\hline $4101-55$ & 41.6 & - & 31.74 & 41.49 & 33.96 \\
\hline $4101-58$ & 61.44 & - & - & 63.92 & 59.56 \\
\hline $4101-61$ & 76.37 & - & - & 77.16 & 77.6 \\
\hline
\end{tabular}
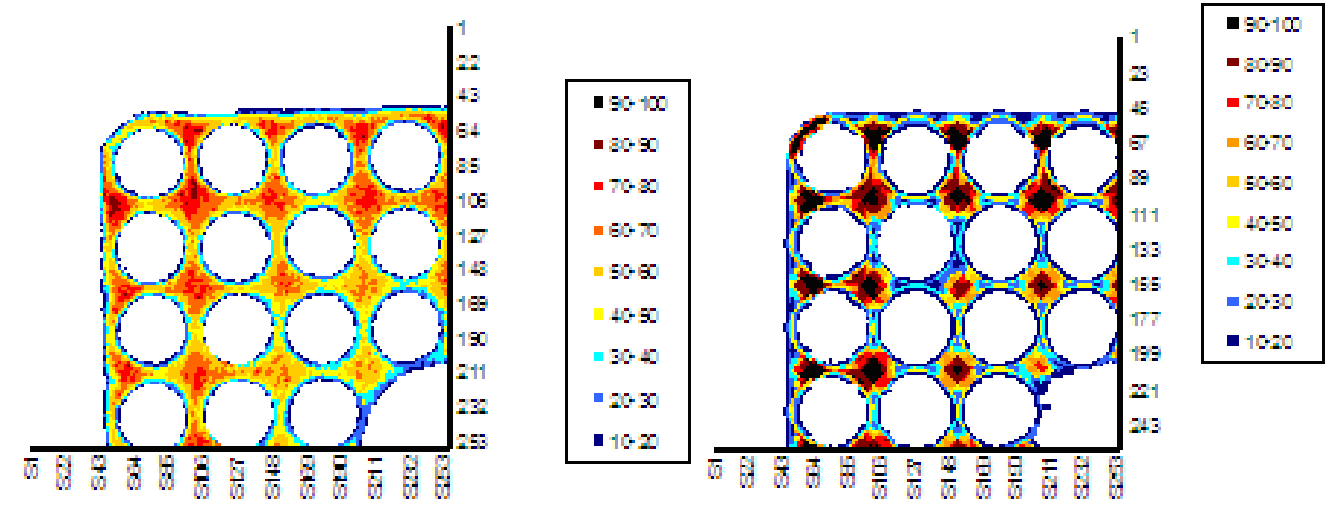

Figure 4. Test case 4101-55 - STAR-CD 3.26 code prediction on the right and experimental measured data on the left

* Corresponding author - e-mail: mna109@psu.edu; Tel.: +1-814-865-0043; Fax: +1-814-865-8499 
Two types of comparisons were performed for Exercise 3 of Phase I. The first type is demonstrated in Figure 5. It was performed in order to evaluate codes performance in the prediction of overall transient behavior. In summary, all codes demonstrated capability of reproducing the transient behavior of the bundle average void fraction for both transient scenarios. Comparisons to data show different tendencies depending in which part of the bundle are made measurements which is associated with measurement uncertainties. For the lower part of the bundle (Figure 5) the codes under-predict void distribution. The second type of comparative analysis was performed to evaluate the accuracy of the codes prediction within the boundaries of $\pm 10 \%$ for selected time periods during the transients and for different subchannel types. The second type of comparative analysis is shown in Figure 6.

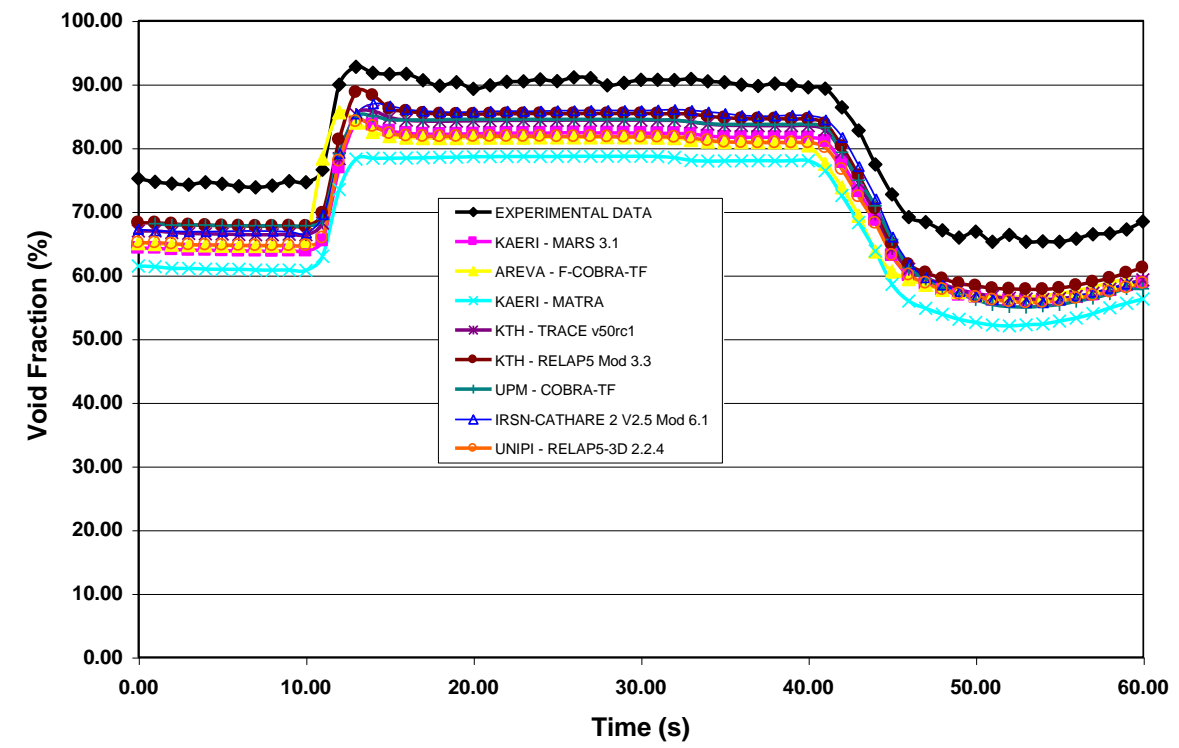

Figure 5. Pump trip transient - chordal averaged void fraction at x-ray DEN \#1 $2730 \mathrm{~mm}$ 


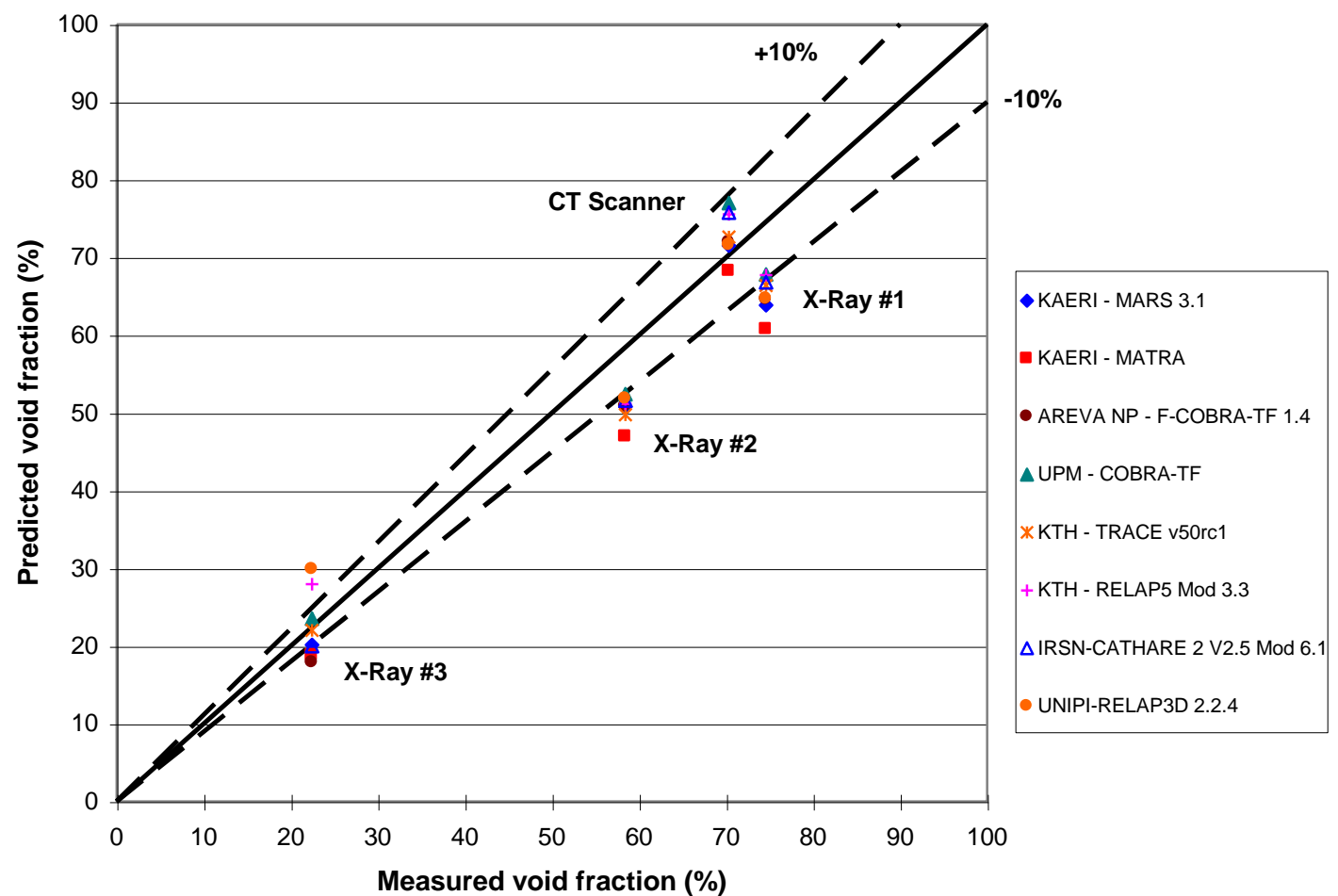

Figure 6. Pump trip - transient time at $10 \mathrm{~s}$

\subsubsection{Phase II - critical power benchmark}

The purpose of the Phase II of the BFBT benchmark (critical power benchmark) is to provide data for the validation of mechanistic models for critical power prediction. Exercise II-0 is a steady-state pressure drop benchmark. Exercise II-1 is a steady-state benchmark, which applies a one-dimensional approach with critical power correlations and a sub-channel mechanistic approach. Exercise II-2 is a transient benchmark, which applies a one-dimensional approach with critical power correlations and a sub-channel mechanistic approach. Exercise II-3 is a benchmark on the uncertainty analysis of critical power prediction.

Table 5 lists the participating organizations who have submitted results for Phase II.

Table 5. List of participants in Phase II of the BFBT benchmark

\begin{tabular}{|c|c|c|c|c|}
\hline P & Abbreviation & Country & Code & Code Type \\
\hline $\begin{array}{c}\text { Korea Atomic Energy } \\
\text { Institute }\end{array}$ & KAERI & Korea & MARS/MATRA & Subchannel \\
\hline Westinghouse & Westinghouse & Sweden & MONA 3 & Subchannel \\
\hline $\begin{array}{c}\text { Royal Institute of } \\
\text { Technology }\end{array}$ & KTH & Sweden & TRACE/RELAP5 & System \\
\hline $\begin{array}{c}\text { Commissariat à l'Énergie } \\
\text { Atomique }\end{array}$ & CEA & France & $\begin{array}{c}\text { NEPTUNE } \\
\text { SYSTEM/FLICA- } \\
4\end{array}$ & System/Subchannel \\
\hline $\begin{array}{c}\text { Nuclear Power } \\
\text { Engineering Corporation }\end{array}$ & NUPEC & Japan & CAPE & Subchannel \\
\hline $\begin{array}{c}\text { AREVA NP GmbH } \\
\text { AREVA }\end{array}$ & Germany & $\begin{array}{c}\text { F-COBRA- } \\
\text { TF/IVA }\end{array}$ & $\begin{array}{c}\text { Subchannel/Porous } \\
\text { Media }\end{array}$ \\
\hline
\end{tabular}

* Corresponding author - e-mail: mna109@psu.edu; Tel.: +1-814-865-0043; Fax: +1-814-865-8499 


\begin{tabular}{|c|c|c|c|c|}
\hline $\begin{array}{c}\text { TEPCO System } \\
\text { Corporation }\end{array}$ & TEPCO & Japan & NASCA & Subchannel \\
\hline $\begin{array}{c}\text { The Pennsylvania State } \\
\text { University }\end{array}$ & PSU & USA & COBRA-TF & Subchannel \\
\hline University of Pisa & UNIPI & Italy & RELAP3D & System \\
\hline $\begin{array}{c}\text { Universidad Politécnica } \\
\text { de Madrid }\end{array}$ & UPM & Spain & COBRA-TF & Subchannel \\
\hline
\end{tabular}

Comparisons of participants' results with the single-phase pressure and two-phase drop measurements taken at several axial elevations along the bundle length were performed. The comparative analyses begin with pressure drop results over the entire heated length, continue with predicted versus measured (P/M) pressure drop results for different pressure taps at various axial elevations, and completes with comparison which provides the $\mathrm{P} / \mathrm{M}$ ratio as a function of the Reynolds number for each code participating in the benchmark. Illustrations of the analyzed results are shown in Figures 7 through 9 on the example of the PSU version of COBRA-TF (CTF) for the single pressure drop case.

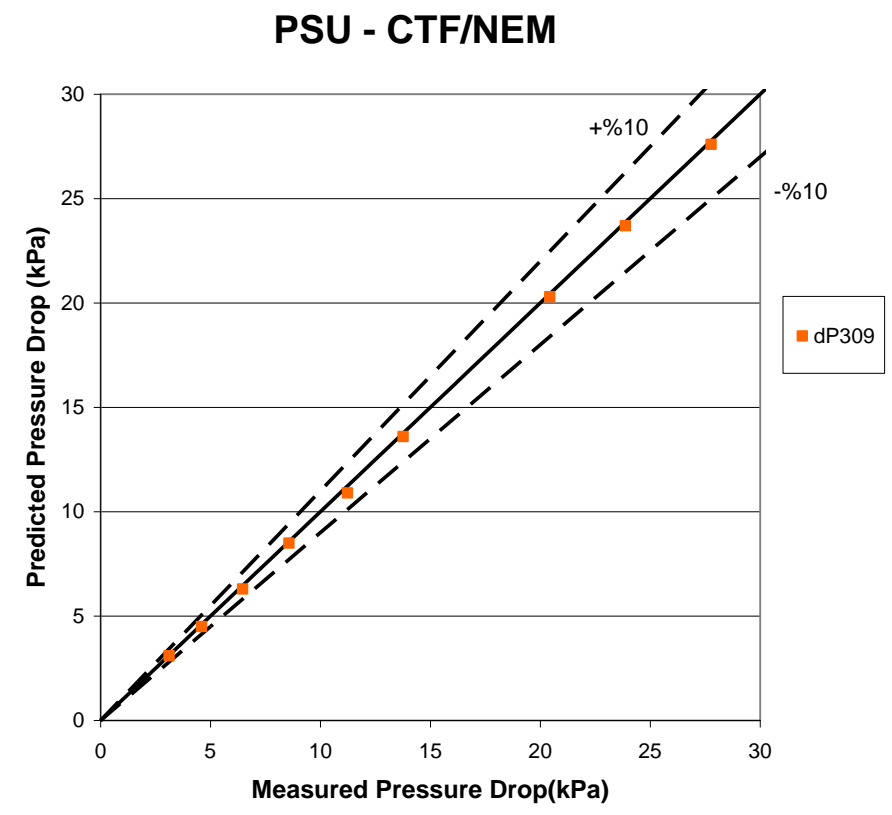

Figure 7. P/M Bundle Overall Pressure Drop Results 


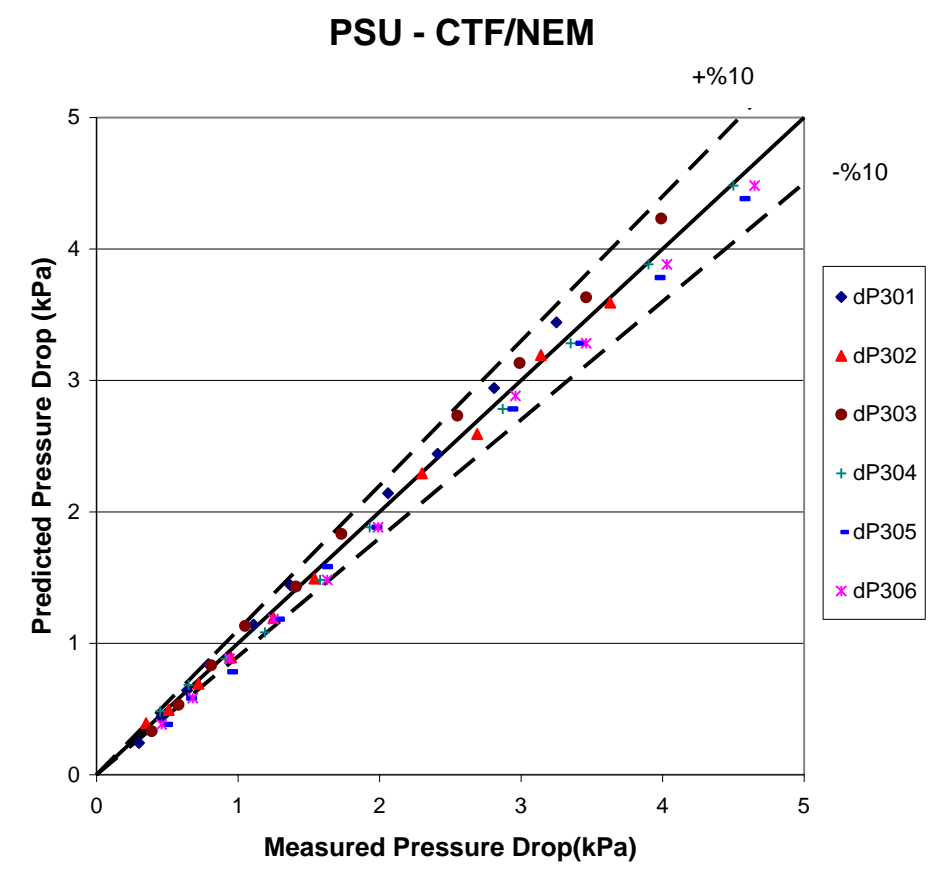

Figure 8. P/M Pressure Drop Results for Different Pressure Taps

\section{PSU - CTF/NEM}

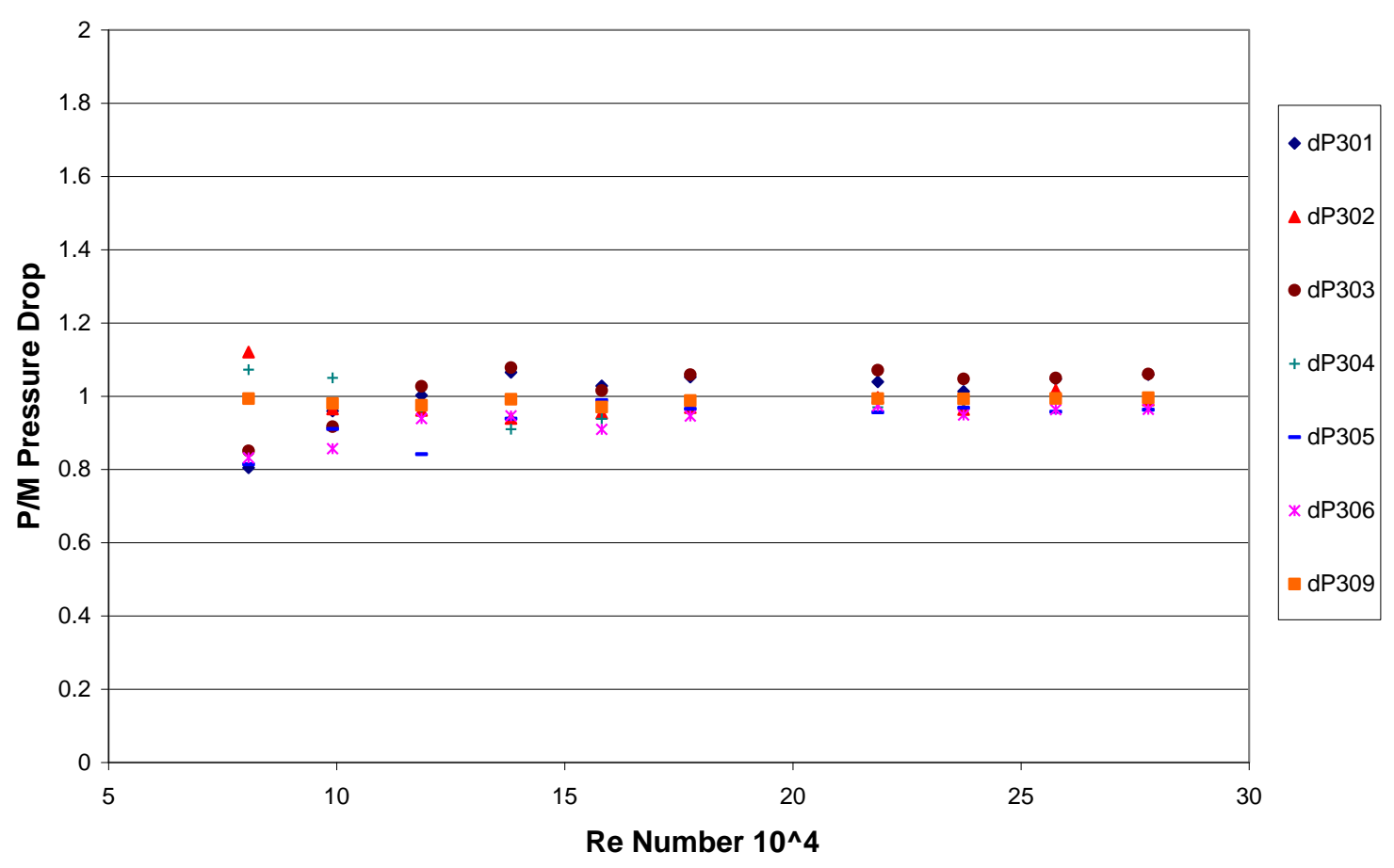

Figure 9. P/M vs. Reynolds number for Different Pressure Taps

* Corresponding author - e-mail: mna109@psu.edu; Tel.: +1-814-865-0043; Fax: +1-814-865-8499 
The pressure drop comparisons have indicated the following tendencies: code predictions are very sensitive to the spacer grid loss coefficients; bias to the flow velocity and the bundle power is observed, and the models for interfacial friction need improvements.

Within the Exercise II-1 steady state critical power results were collected and analyzed. The purpose was to assess and compare different models for prediction of critical power to experimental data on a prototypical BWR rod bundle. Exercise II-2 is focused on transient critical power predictions and comparisons with measured values. Based on the performed comparative analysis the following observations have been made regarding capabilities for critical power predictions, which constitute "lessons learned" from Phase II of the BFBT benchmark:

a) The accuracy of the critical power predictions depends on the critical power modeling approach, liquid film thickness modeling, onset of annular-mist flow criteria, droplet entrainment and deposition models, spacer grid effects on the critical power and cross flow models

b) Most of the codes have shown scatter larger than $10 \%$ with a pronounced tendency of an overprediction

c) Bias with the BCs has been often observed

d) Good agreement with the measured transient critical power/rewetting time was observed.

The purpose of Exercise I-4 (uncertainty of void distribution) and Exercise II-3 (uncertainty analysis of critical power) was to apply techniques of uncertainty analysis and to assess the accuracy of thermalhydraulic models for void distribution and critical power prediction in rod bundles. These exercises were merged in Exercise II-3 of the on-going OECD LWR UAM benchmark and will be discussed in the section devoted to this benchmark.

\section{OECD/NRC PSBT Benchmark}

\subsection{Objectives}

One of the most valuable databases identified for the thermal-hydraulics modeling was developed by the Nuclear Power Engineering Corporation (NUPEC), Japan, which includes subchannel void fraction and departure from nucleate boiling (DNB) measurements in a representative Pressurized Water Reactor (PWR) fuel assembly. From 1987 to 1995, NUPEC performed a series of void measurement tests using full-size mock-up tests for both BWRs and PWRs. Void fraction measurements and departure from nucleate boiling (DNB) tests were performed at NUPEC under steady-state and transient Pressurized Water Reactor (PWR) conditions. Part of this database is made available for an international benchmark activity entitled as the OECD/NRC NUPEC PWR Subchannel and Bundle Tests (PSBT) benchmark [5]. This international project is officially approved by the Japan METI, U.S. NRC, and endorsed by the OECD/NEA/NSC. The benchmark team is organized based on the collaboration between Japan and USA.

The PSU under the sponsorship of the US NRC has prepared, organized, conducted and summarized the OECD/NRC Benchmark Based on NUPEC PWR Subchannel and Bundle Tests (PSBT). The international benchmark activities have been conducted in cooperation with the OECD/NEA and JNES, Japan. The JNES has made available the PWR Nuclear Power Engineering Corporation (NUPEC) experimental database for the purposes of the OECD/NRC PSBT international benchmark and has asked PSU to organize and conduct this benchmark activity. The OECD/NRC PSBT Benchmark is organized to provide a test bed for assessing the capabilities of various thermal-hydraulic subchannel, system, and computational fluid dynamics (CFD) codes. The benchmark is designed to systematically assess and compare the participants' numerical models for prediction of detailed subchannel void distribution and DNB, under steady-state and transient conditions, to full-scale experimental data. It consists of seven exercises grouped in two phases. In an attempt to determine the strengths and weaknesses of the models utilized in each code, code-to-code comparisons are performed in addition to the code-to-data assessment.

* Corresponding author - e-mail: mna109@psu.edu; Tel.: +1-814-865-0043; Fax: +1-814-865-8499 
The fine-mesh high-quality subchannel void fraction and departure from nucleate boiling data encourages advancement in understanding and modeling complex flow behavior in real rod bundles. Considering that the present theoretical approach is relatively immature, the benchmark specification is designed to systematically assess and compare the participants' analytical models on the prediction of detailed void distributions and DNB. It should be recognized that the purpose of this benchmark is not only the comparison of currently available computational approaches but above-all the encouragement to develop novel next-generation approaches that focus on more microscopic processes.

The benchmark consists of two phases with a total of seven exercises.

\subsection{Summary of results}

\subsubsection{Phase I - void distribution benchmark}

The exercises in Phase I (Void distribution benchmark) of the benchmark are designed to test the codes' ability to predict void distribution in a single subchannel and a bundle under both steady-state and transient conditions, as well as to calculate the pressure drop across a bundle. Exercise I-1 is focused on steady-state single subchannel void calculation while Exercise I-2 deals with steady-state bundle void distribution predictions. Exercise I-3 is a transient bundle void distribution benchmark. Exercise I-4 is pressure drop benchmark.

Detailed comparative analysis of submitted participants' results for different exercises of the two phases of the benchmark was performed. In this paper selected examples are shown to illustrate the methodology of comparisons and indicate the observed tendencies. For example, there were a total of twenty (20) participants for Exercise 1 of Phase I. Table 6 lists these participants, as well as the codes for which results were submitted.

Table 6. Phase I Exercise 1 Participants and Code List

\begin{tabular}{||l|l|l||}
\hline Participant & Code & Code Type \\
\hline \hline ANL & STAR-CD & CFD \\
\hline ANSYS & ANSYS & CFD \\
\hline EDF & NEPTUNE & CFD \\
\hline GRS & ANSYS-CFX & CFD \\
\hline HZDR & ANSYS-CFX & CFD \\
\hline PSI & STAR-CD & CFD \\
\hline EDF & THYC & Porous media \\
\hline AREVA & F-COBRA-TF & Subchannel \\
\hline CEA-Saclay & FLICA-OVAP & Subchannel \\
\hline CSA & VIPRE & Subchannel \\
\hline JNES & CHAMP-ITA & Subchannel \\
\hline KAERI & MATRA & Subchannel \\
\hline KIT & SUBCHANFLOW & Subchannel \\
\hline McMaster & ASSERT-PV & Subchannel \\
\hline PSI & FLICA & Subchannel \\
\hline CEA-Grenoble & CATHARE 3 & System \\
\hline IRSN & CATHARE 2 & System \\
\hline KTH & TRACE & System \\
\hline PSI & TRACE & System \\
\hline
\end{tabular}

* Corresponding author - e-mail: mna109@psu.edu; Tel.: +1-814-865-0043; Fax: +1-814-865-8499 
Statistical methodology has been utilized for comparative analysis. Mean error and standard deviation were calculated for each code for each test series. Test series differ by test section (subchannel vs. $5 \times 5$ rod bundle) and each test series include different test conditions. Figure 10 summarizes the mean error of participant void fraction calculations as compared to measurements, while Figure 11 summarizes the standard deviation of those results. There was no clear bias in the calculation of void fraction for any of the four subchannels. Although some of the codes consistently predicted the correct thermal equilibrium quality, there was a tendency to overpredict it at the low elevation and underpredict it at the high elevation.

Similar comparative analysis is performed for the rest of the exercises in Phases I and II. In the results for the first phase, it was observed that the codes tended to overpredict the thermal equilibrium quality at lower elevations and underpredict it at higher elevations. There was also a tendency to overpredict void fraction at lower elevations and underpredict it at high elevations for the bundle test cases. Some of the best results were achieved by codes that used either turbulent mixing or dispersion terms for modeling cross-flow.

For Exercise I-3 (Transient rod bundle) the available data for this exercise consisted of chordal-averaged $\mathrm{x}$-ray densitometer measurements of fluid density in the rod bundle. The measured density was then used to calculate the void fraction. The given values are the average of the void fraction over the four central subchannels of the bundle. Four transient scenarios (temperature increase, power increase, depressurization, and flow reduction) were used in this exercise for each test series, yielding twelve total test cases. As example the CTF (sub-channel) predictions and TRACE (system) predictions of void fraction in bundle type B5 during flow reduction transient are shown in Figure 12 and compared to available measured data. Please note that the measured data is provide with experimental uncertainties. A slight time shift can be seen in the void fraction results when they are compared to the experimental data for the temperature increase cases. It has been suggested that the structure between the downcomer and test section was not truly adiabatic and, as a result, there was some heat transfer between these regions that was responsible for this shift. Aside from that observation, the codes generally performed well in predicting the void fraction throughout the different transients, yielding better results at the highest elevation in the bundle and worse results at the lowest elevation.

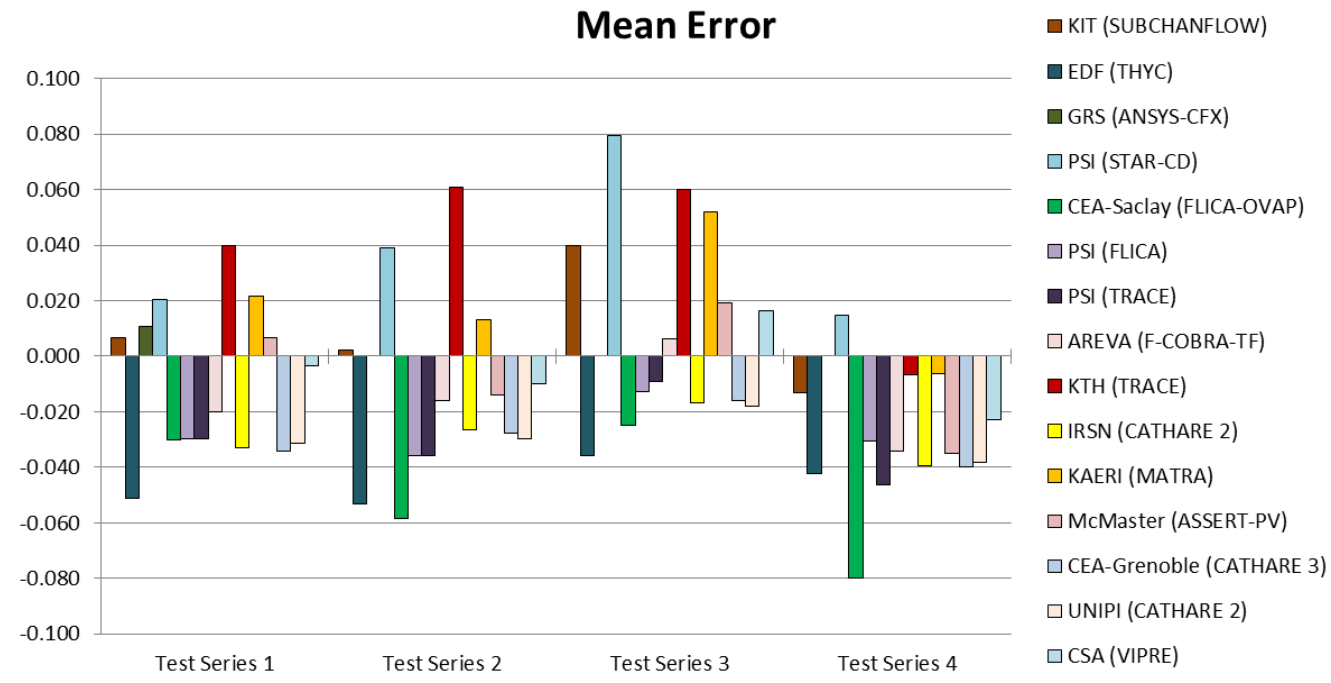

Figure 10. Void Fraction Mean Error by Test Series

\footnotetext{
* Corresponding author - e-mail: mna109@psu.edu; Tel.: +1-814-865-0043; Fax: +1-814-865-8499
} 


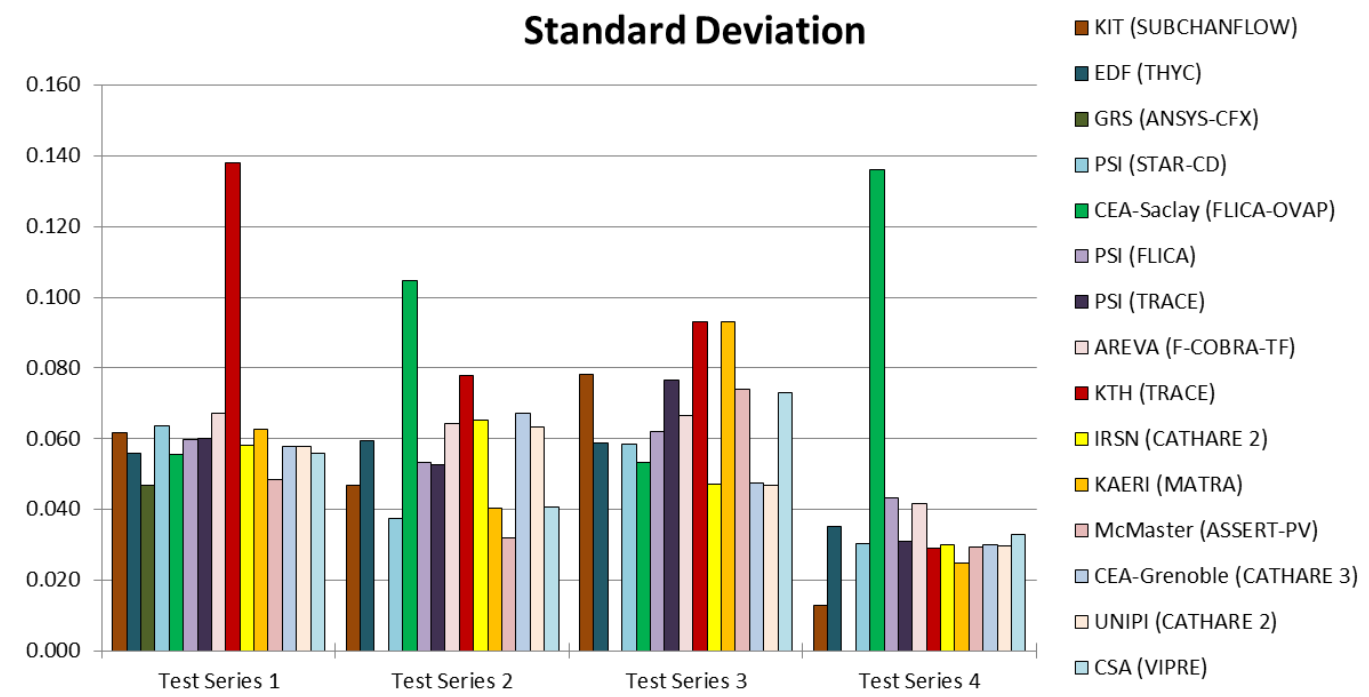

Figure 11. Void Fraction Standard Deviation by Test Series
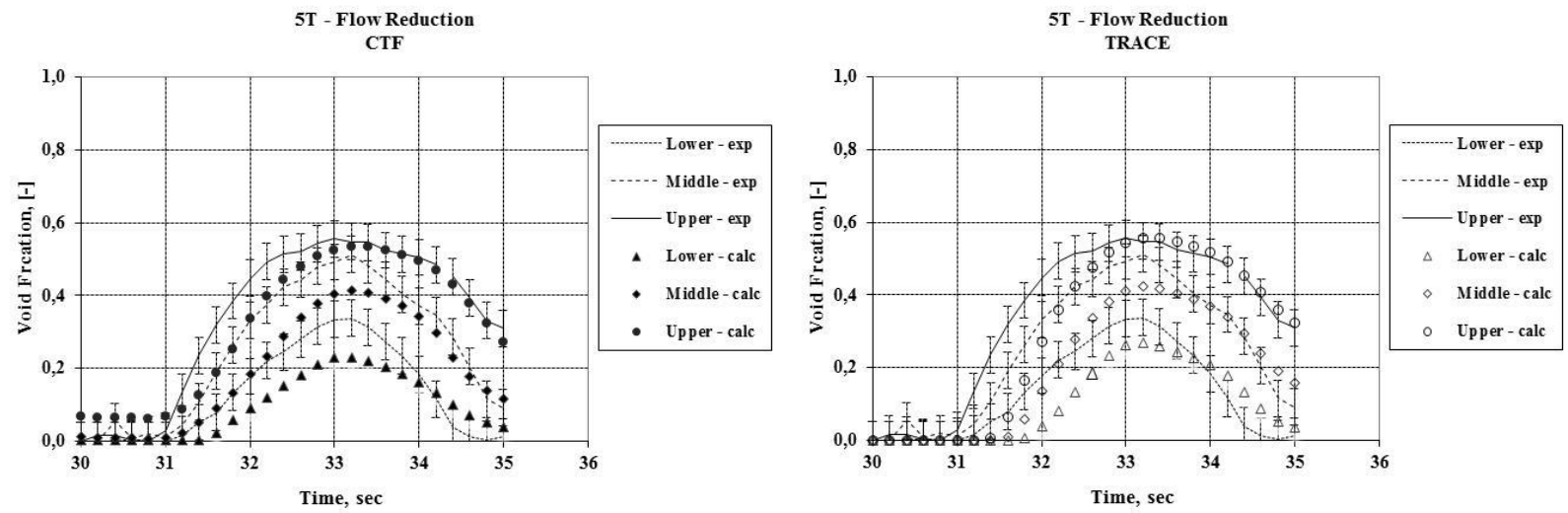

Figure 12. CTF (left) and TRACE (right) Predictions of Void Fraction in Bundle Type B5 during Flow Reduction Transient

\subsubsection{Phase II - DNB benchmark}

The exercises in Phase II (DNB benchmark) of the benchmark are designed to test the codes' ability to predict DNB in a bundle assembly under both steady-state and transient conditions, as well as to predict fluid temperatures under these conditions. Exercise II-1 is steady-state fluid temperature benchmark, Exercise II-2 is focused on steady state DNB calculation while Exercise II-3 deals with transient DNB predictions.

Based on the final results for the second phase, a number of conclusions were drawn, which constitute "lessons learned" from this benchmark phase. The codes were generally able to replicate the results of the mixing test, within 5\% of the experimental fluid exit temperature. In exercises 2 and 3 of Phase II, the codes were generally able to predict the DNB power as well as the axial location of the onset of Departure of Nucleate Boiling (DNB) (for the steady-state cases) and the time of DNB (for the transient cases).

This benchmark was summarized in a special issue entitled "Selected Papers from OECD-NEA PSBT Benchmark" in the International Journal of Science and Technology of Nuclear Installations, in 2013.

\footnotetext{
* Corresponding author - e-mail: mna109@psu.edu; Tel.: +1-814-865-0043; Fax: +1-814-865-8499
} 


\section{OECD Kalinin-3 Coolant Transient Benchmark}

\subsection{Objectives}

The reference problem of Kalinin-3 (K-3) benchmark chosen for simulation is Main Circulation Pump (MCP) \#1 switching off at nominal power when the other three main coolant pumps are in operation, which is a real transient of an operating VVER-1000 power plant. This event is characterized by rapid rearrangement of the coolant flow through the reactor pressure vessel resulting in a coolant temperature change, which is spatially dependent. This leads to insertion of spatially distributed positive reactivity due to the moderator feedback and a non-symmetric power distribution. Simulation of the transient requires evaluation of core response from a multi-dimensional perspective (coupled 3D neutronics/core thermalhydraulics) supplemented by a one-dimensional (1D) simulation of the remainder of the reactor coolant system. The purpose of this benchmark is three-fold:

a) To verify the capability of system codes to analyze complex transients with coupled core-plant interactions and complicated fluid mixing phenomena;

b) To fully test the 3D neutronics/thermal-hydraulic coupling;

c) To evaluate discrepancies between predictions of the coupled codes in best-estimate transient simulations with measured data.

The benchmark specification is based on NEA/OECD VVER-1000 Coolant Transient Benchmark (V1000CT-1) [8] and on the experimental data description [9] officially delivered from the Russian institutions to the OECD/NEA.

The benchmark includes a set of input data for the NPP Kalinin-3 and consists of three exercises.

a) Exercise 1 - Point kinetics plant simulation.

The purpose of this exercise is to test the primary and secondary system model responses. Provided are compatible point kinetics model inputs, which preserve the axial and radial power distribution, and control rod (CR) groups \#10 and \#9 reactivity obtained using a 3D code neutronics model and a complete system description.

b) Exercise 2 - Coupled 3-D neutronics/core thermal hydraulic $(T-H)$ response evaluation.

The purpose of this exercise is to model the core and the vessel only. Inlet and outlet core transient boundary conditions are provided by the benchmark team on the basis of calculations performed with ATHLET-BIPR-VVER coupled code system or the participants can apply the measured data. Hot full power (HFP) state (Exercise \#2a) of the core is required for comparison.

c) Exercise 3 - Best-estimate coupled code plant transient modeling.

This exercise combines elements of the first two exercises in this benchmark and is an analysis of the transient in its entirety.

In the frame of the OECD Benchmark for Uncertainty Analysis in Best-Estimate Modelling (UAM) for Design, Operation and Safety Analysis of LWRs (UAM-LWR) [10] it is foreseen to continue activities in the K-3 benchmark and to perform Exercise 4 of uncertainty analysis as a part of Phase-III of the before mentioned LWR-UAM benchmark.

\footnotetext{
* Corresponding author - e-mail: mna109@psu.edu; Tel.: +1-814-865-0043; Fax: +1-814-865-8499
} 


\subsubsection{Transient scenario}

The transient scenario (recovered from the measured data histories) is listed shortly below. The time interval of interest is $300 \mathrm{~s}$.

- Manually switching off of main coolant pump (MCP) \#1 at $\mathrm{t}=0 \mathrm{~s}$.

- After the signal 'one pump out of operation' which is generated after $1.41 \mathrm{~s}$, reactor limiting controller starts to decrease the power to a level of $67.2 \%$.

- :

- At $\mathrm{t}=1.41 \mathrm{~s}$ the reactor limiting controller starts to decrease the reactor power. CR \#10 starts to move downwards. When the CR \#10 reaches $50 \%$ insertion depth (at about 60 s) the CR \#9 starts also to enter the active core according to the control rod movement algorithm.

- At $t=71 \mathrm{~s}$ the reactor power load-off procedure is cancelled and power reaches a level of $67.2 \%$ $\mathrm{P}_{\text {nom. }}$. At this moment the position of the CR \#10 is at $43.4 \%$ and remains till the end of the transient at this position. CR \#9 is inserted into the core and reaches at $71 \mathrm{~s}$ the position of $93.1 \%$ and keeps it till $180 \mathrm{~s}$ after which it returns back to $100 \%$. With the reactor limiting controller the reactor power was decreased from $98.9 \% \mathrm{P}_{\text {nom }}$ to $67.2 \% \mathrm{P}_{\text {nom }}$ within $71 \mathrm{~s}$. The speed of reactor power decrease (load-off) within the reactor limiting controller operations is $26.8 \% / \mathrm{min}$. The change of the coolant heat-up in the core decreases from $29^{\circ} \mathrm{C}$ to $23.3^{\circ} \mathrm{C}$.

- Due to reactor limiting controller operation and switching off of automatic reactor power controller, the electronic controller of the turbine generator electro-hydraulic automatic controller starts the load-off operation of the turbine generator. At $t=222 \mathrm{~s}$ the power of the turbine generator corresponds to the reactor power and stabilizes at $625.5 \mathrm{MW}$.

- The pressure in the main steam line changes from initial 6.01 MPa to a level of 5.86-6.02 MPa. At $300 \mathrm{~s}$ the pressure is stabilized at $6.02 \mathrm{MPa}$.

- Primary pressure changes from initial 15.52 MPa to 15.12 -15.56 MPa following the change of the mean primary coolant temperature.

- At $94 \mathrm{~s}$ of the transient the pressure is stabilized at $15.13 \mathrm{MPa}$. Due to the pressurizer heaters operation starting from $140 \mathrm{~s}$ the pressure starts to increase and at $300 \mathrm{~s}$ it stabilizes at $15.47 \mathrm{MPa}$. As a result the pressurizer level changes from $858.5 \mathrm{~cm}$ at the beginning to $801.1 \mathrm{~cm}$ at the end of the transient.

During the transient the maximum coolant temperature measured at the assemblies' outlets is registered at $46 \mathrm{~s}$ and has a raise of approximately $3^{\circ} \mathrm{C}$. The maximum raise $\left(2.8^{\circ} \mathrm{C}\right)$ of the hot loop temperature is observed in loop \#3. The cold loop coolant temperatures at the loops where the pumps remain in operation change as follows: loop $\# 2-3.7^{\circ} \mathrm{C}$; loop $\# 3-2.8^{\circ} \mathrm{C}$ and loop $\# 4-4.8^{\circ} \mathrm{C}$. It is observed that as a result of the switching off of MCP \#1 the main part of the coolant with lower temperature of hot leg \#1 moves into the hot leg \#4. Therefore, the coolant flow with the lowest mean temperature reaches SG \#4 and it has also the lowest outlet temperature.

The measurement of the total power has a relative error of $2 \%$. With regard to the fuel assembly axial power the maximum measurement relative error reaches $5 \%$. Lastly the thermocouples measure coolant temperature with a precision of $1^{\circ} \mathrm{C}$. It is to be mentioned that the measurement errors are to be understood as three times standard deviation.

\footnotetext{
* Corresponding author - e-mail: mna109@psu.edu; Tel.: +1-814-865-0043; Fax: +1-814-865-8499
} 


\subsection{Summary of results for Exercise 3}

The following section shows an excerpt of the comparative analyses of the submitted results for Exercise 3. In total, 7 results were submitted by participants representing 6 organizations from 5 countries. Table 7 shows the list of the participants in Exercise 3 together with the names of the codes used for simulation of Exercise 3. It is important to note that three (3) different cross-section libraries were used for this benchmark, which gives an opportunity to evaluate uncertainties introduced with different cross-section libraries. Originally, the cross-section library was based on TVS-M code calculations and provided in a format similar to the format used for the OECD/NEA V1000CT benchmark. On a later stage, during the technical sessions of the benchmark workshops, it was decided another (second) cross-section library to be generated with HELIOS. The decision was substantiated by the lack of Assembly Discontinuity Factors (ADFs) in the thermal group of the original cross-section library, which can lead to "incorrect implementation of the data in a number of nodal core models". The third library based on SAPFIR_95\&RC_VVER was used only by Gidropress since this an established tool for their code system.

Table 7. List of participants in Exercise 3

\begin{tabular}{|c|l|l|l|l|}
\hline$\#$ & \multicolumn{1}{|c|}{ Organization } & \multicolumn{1}{|c|}{ Country } & \multicolumn{1}{c|}{ Code system } & \multicolumn{1}{c|}{$\begin{array}{c}\text { Cross-section } \\
\text { Library }\end{array}$} \\
\hline 1 & Gidropress (GP) & Russia & KORSAR & $\begin{array}{l}\text { SAPFIR_95\&RC_V } \\
\text { VER }\end{array}$ \\
\hline 2 & ÚJV ̌̌ež & Czech Republic & $\begin{array}{l}\text { DYN3D/ATHLET } \\
(2.1 \mathrm{~A})\end{array}$ & $\begin{array}{l}\text { TVSM KI, HELIOS } \\
\text { PSU }\end{array}$ \\
\hline 3 & HZDR & Germany & DYN3D/ATHLET & TVSM KI \\
\hline 4 & $\begin{array}{l}\text { GRS/Kurchatov Institute } \\
\text { (GRS/KI) }\end{array}$ & Germany/Russia & BIPR/ATHLET & TVSM KI \\
\hline 5 & GRNSPG UNIPISA & Italy & RELAP53D/NESTLE & HELIOS PSU \\
\hline 6 & REL & Bulgaria & RELAP5-HD/NEM & HELIOS PSU \\
\hline
\end{tabular}

Twenty (20) different sets of time histories together with axial nodal powers at fourteen (14) selected fuel assemblies (SFA), where self-powered neutron detectors (SPND) are installed, were submitted by the participants for which plant measured data exists. The comparison of time histories of the reactor power level relative errors (RE) between calculated and experimental values are shown in Figure 13. It is noticeable that the predictions of UJV, HELIOS and REL differ from the rest especially after 70 seconds in the transient. This difference is coming from the cross-section library. Figure 14 shows a reasonably good agreement of the average reactor coolant system pressure between the participants' results and measured values in terms of time history of RE between calculated and experimental values. The time history of RE between calculated and experimental values of temperature in cold leg 1, shown in Figure 15 , clearly shows that the largest deviation occurs at the moment of flow reversal. Even then the relative error is less than $1.5 \%$.

The Figure 16 through Figure 18 show three snapshots of axial nodal power at SFA\#3, which is placed in the affected sector \#1. Only four participants have provided the nodal power distributions. All calculations represent satisfactorily the initial axial power profile, whereas during the transient the discrepancy between GP KORSAR calculation and experimental values are increasing. The same picture can be observed for the SFA\#10, which is placed in the opposite to the affected sector \#4 (see Figure 19

* Corresponding author - e-mail: mna109@psu.edu; Tel.: +1-814-865-0043; Fax: +1-814-865-8499 
through Figure 21). The major reason for these larger than expected discrepancies is the cross-section library utilized. GP KORSAR used its own cross-section library for this simulation. Results for two assemblies are shown to underline a different behavior between the two assemblies located differently in reference to the affected loop.

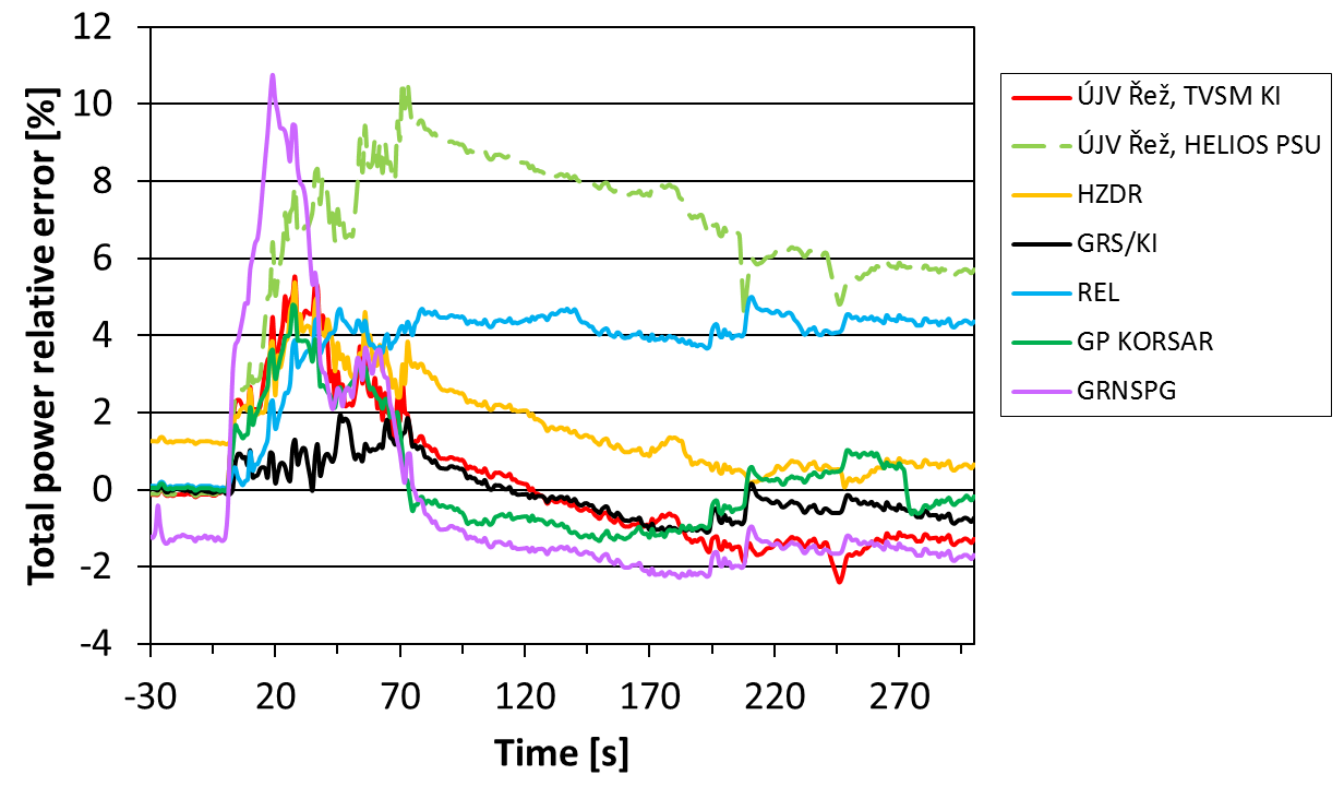

Figure 13. Time history of power relative error

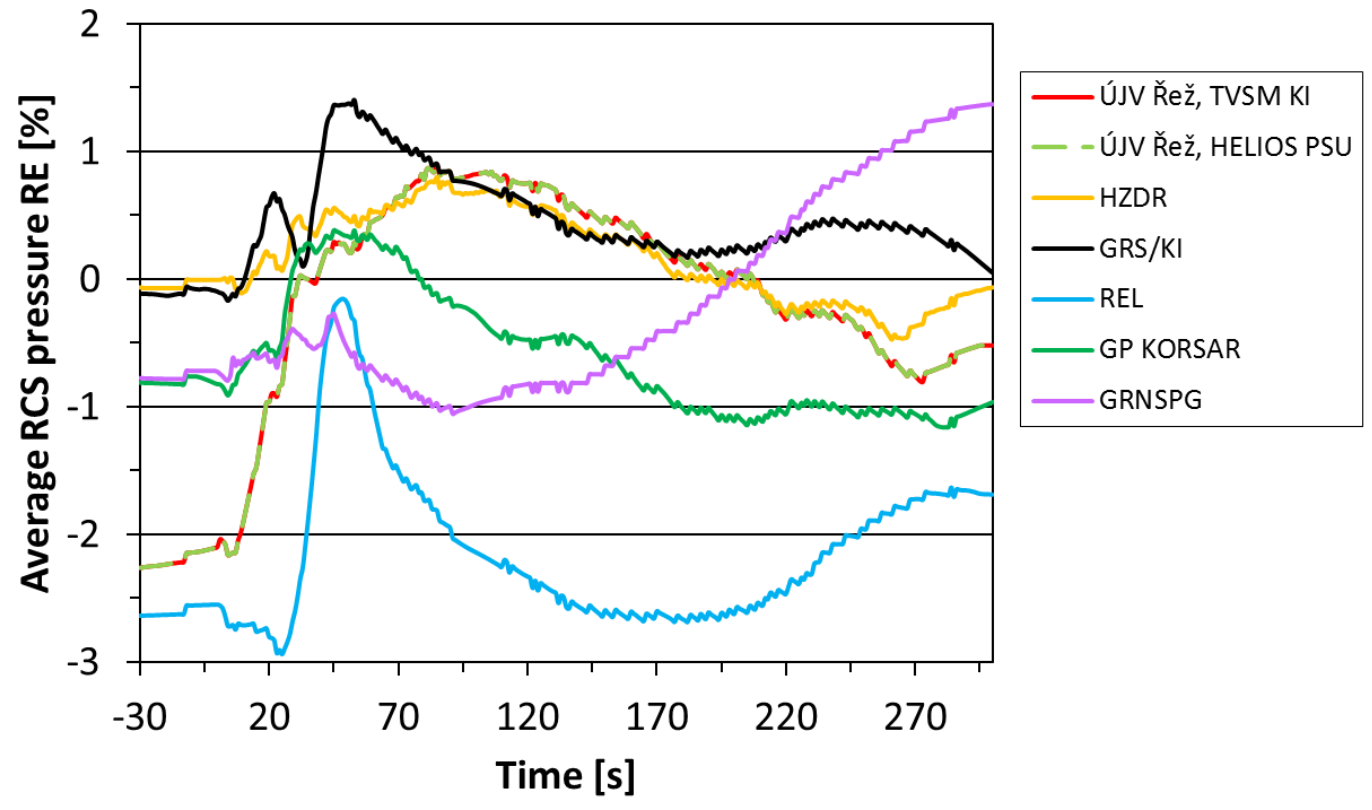

Figure 14. Time history of the average reactor coolant system (RCS) pressure relative error (RE)

* Corresponding author - e-mail: mna109@psu.edu; Tel.: +1-814-865-0043; Fax: +1-814-865-8499 


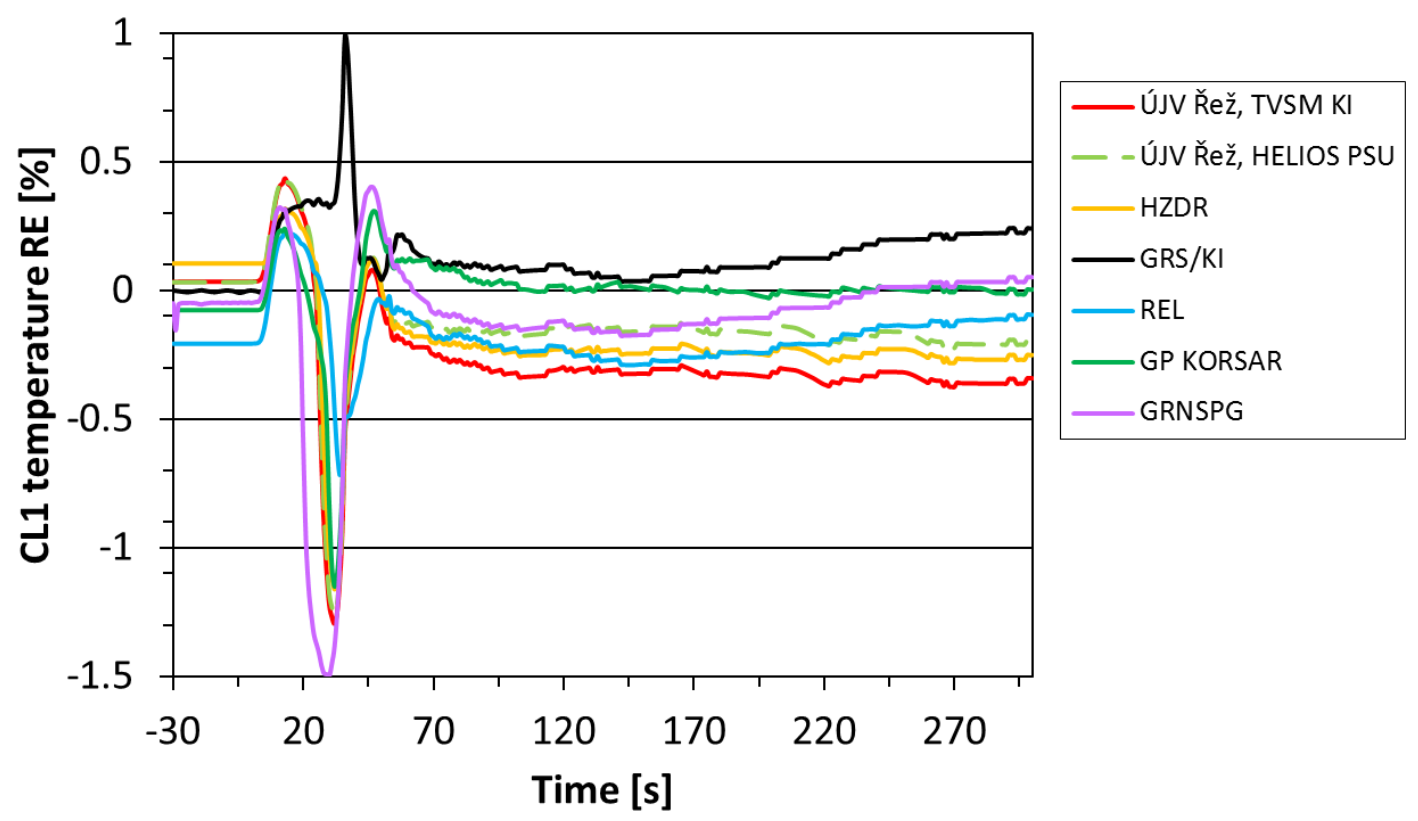

Figure 15. Time history of the cold leg 1 (CL1) temperature relative error (RE)

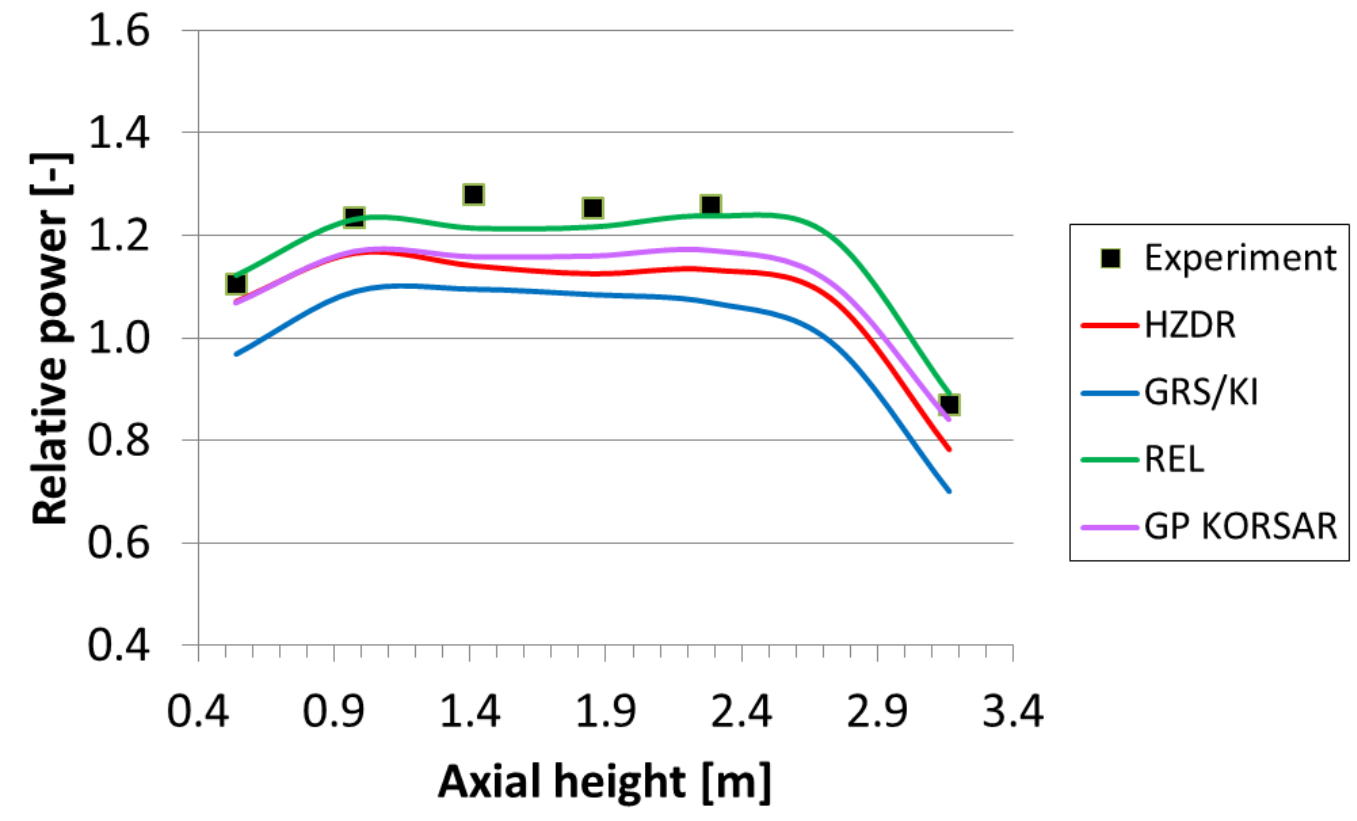

Figure 16. Snapshot of relative axial nodal power at SFA\#3 at $\mathrm{t}=0 \mathrm{~s}$ 


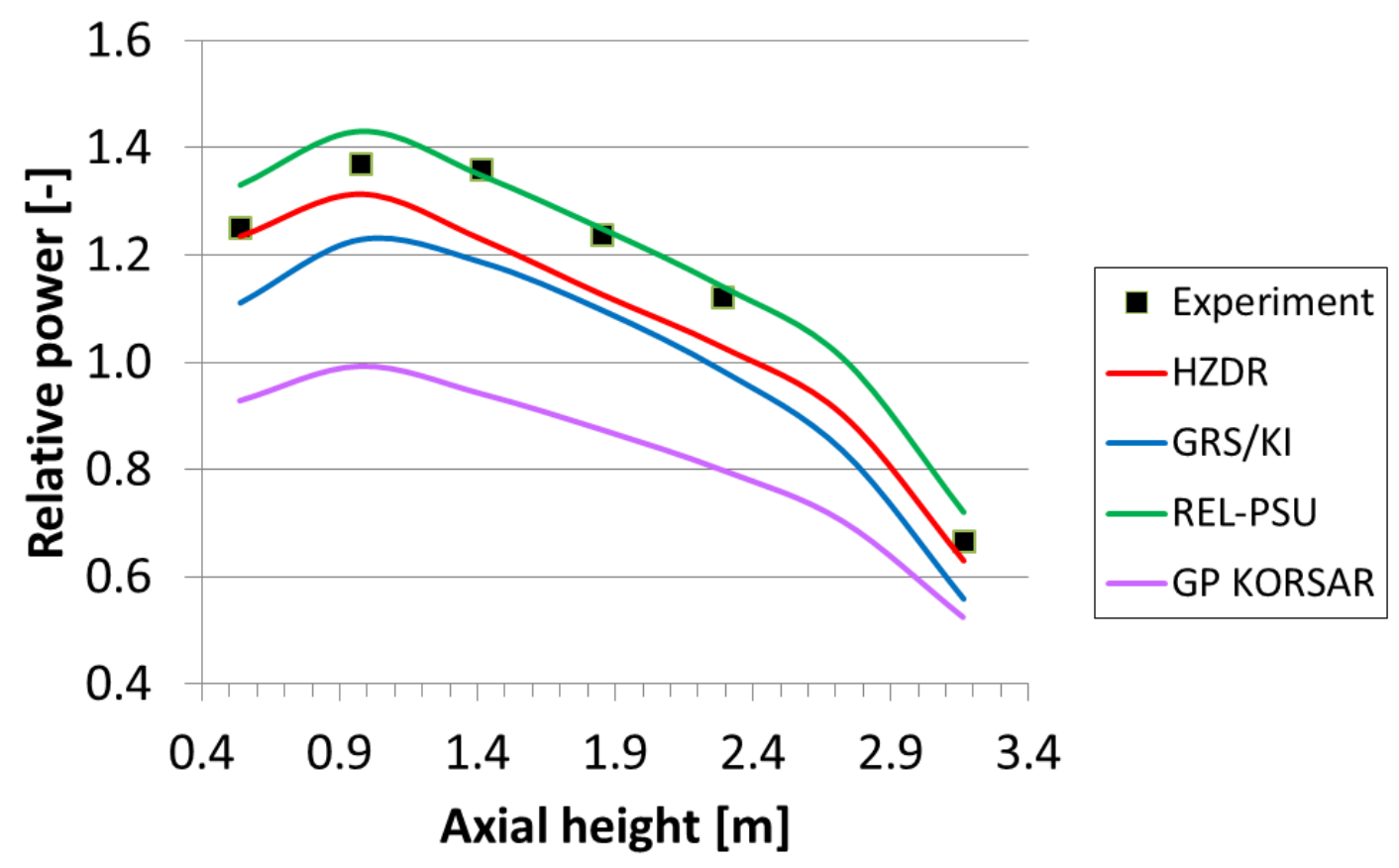

Figure 17. Snapshot of relative axial nodal power at SFA\#3 at $\mathrm{t}=45 \mathrm{~s}$

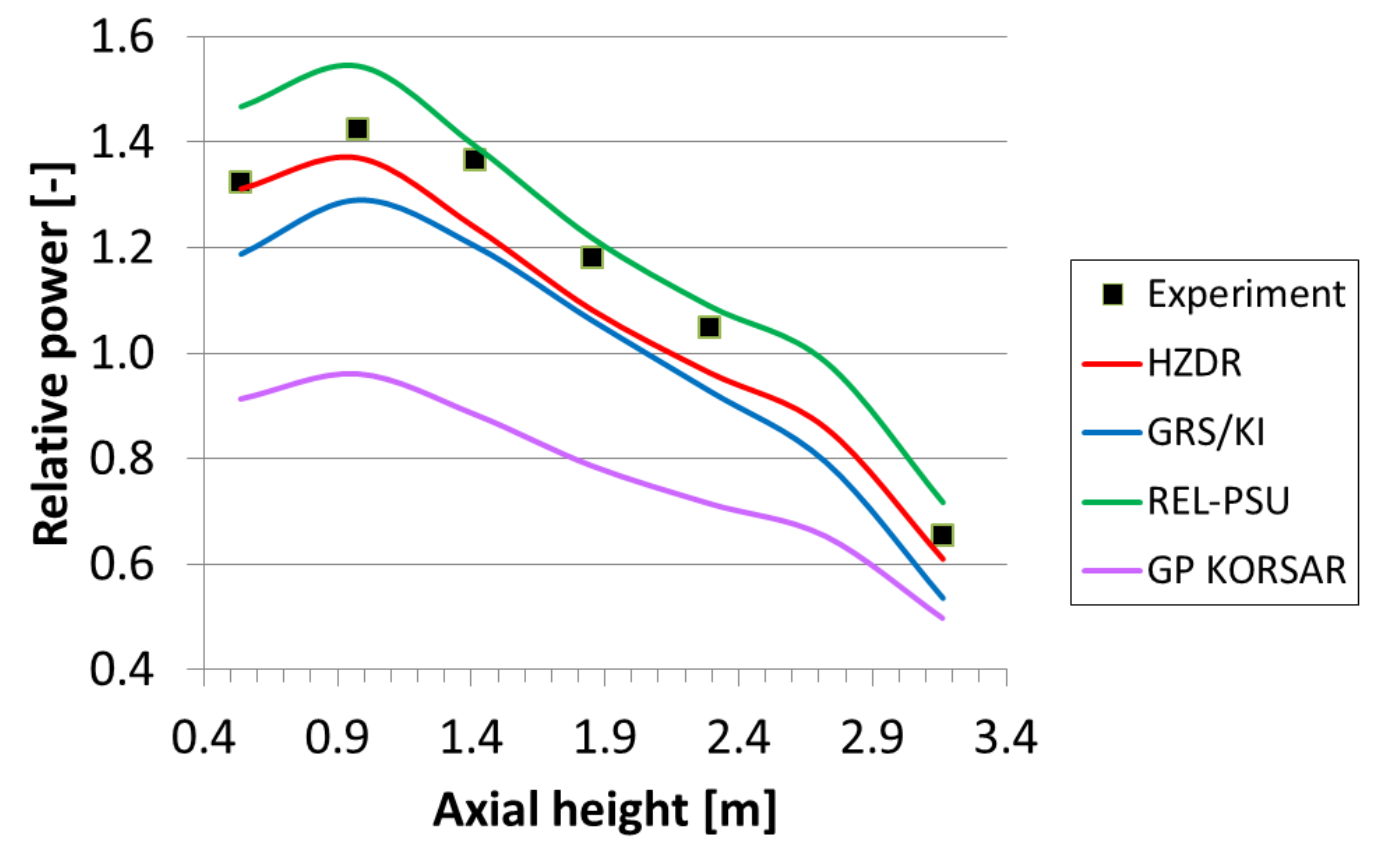

Figure 18. Snapshot of relative axial nodal power at $\mathrm{SFA \# 3}$ at $\mathrm{t}=300 \mathrm{~s}$ 


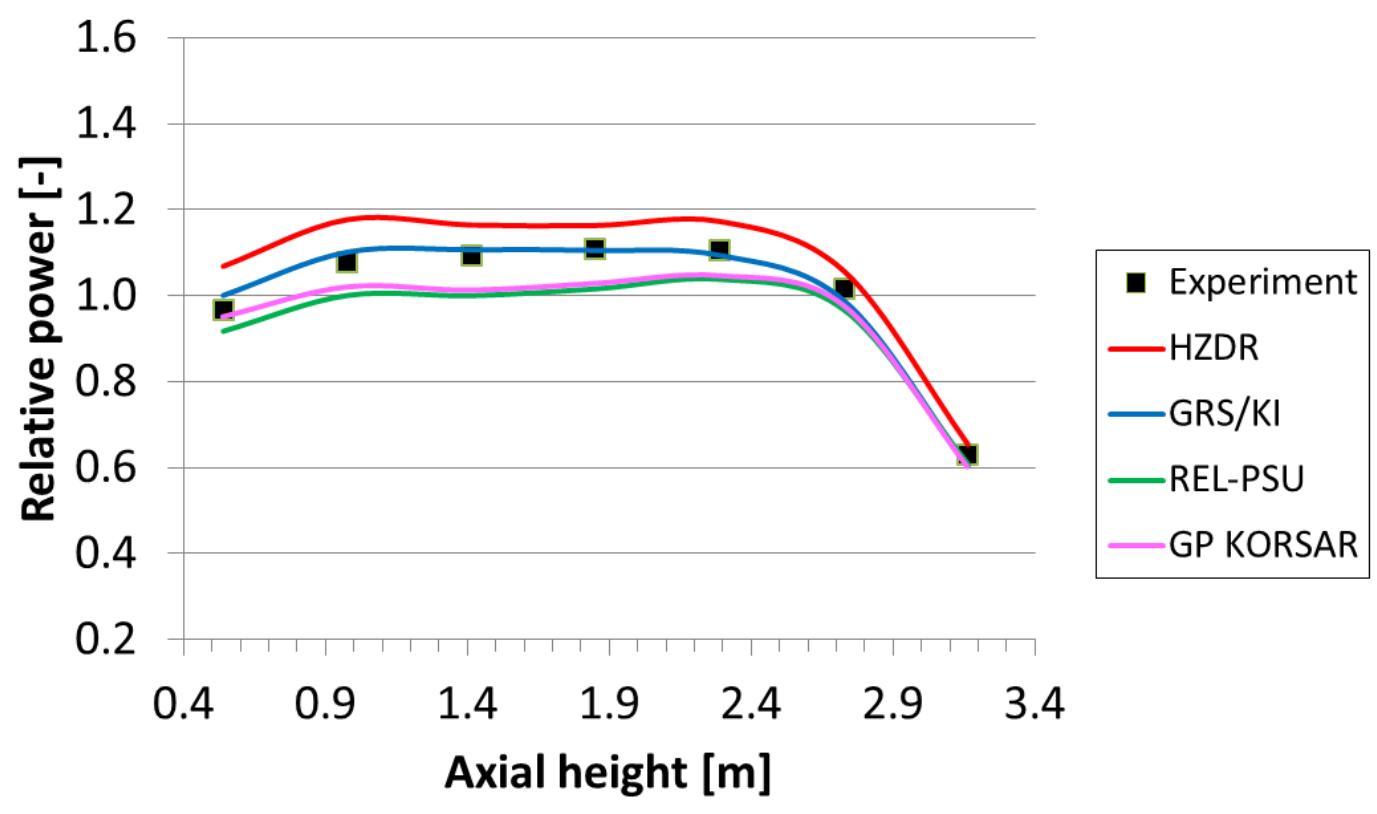

Figure 19. Snapshot of relative axial nodal power at SFA\#10 at $t=0 \mathrm{~s}$

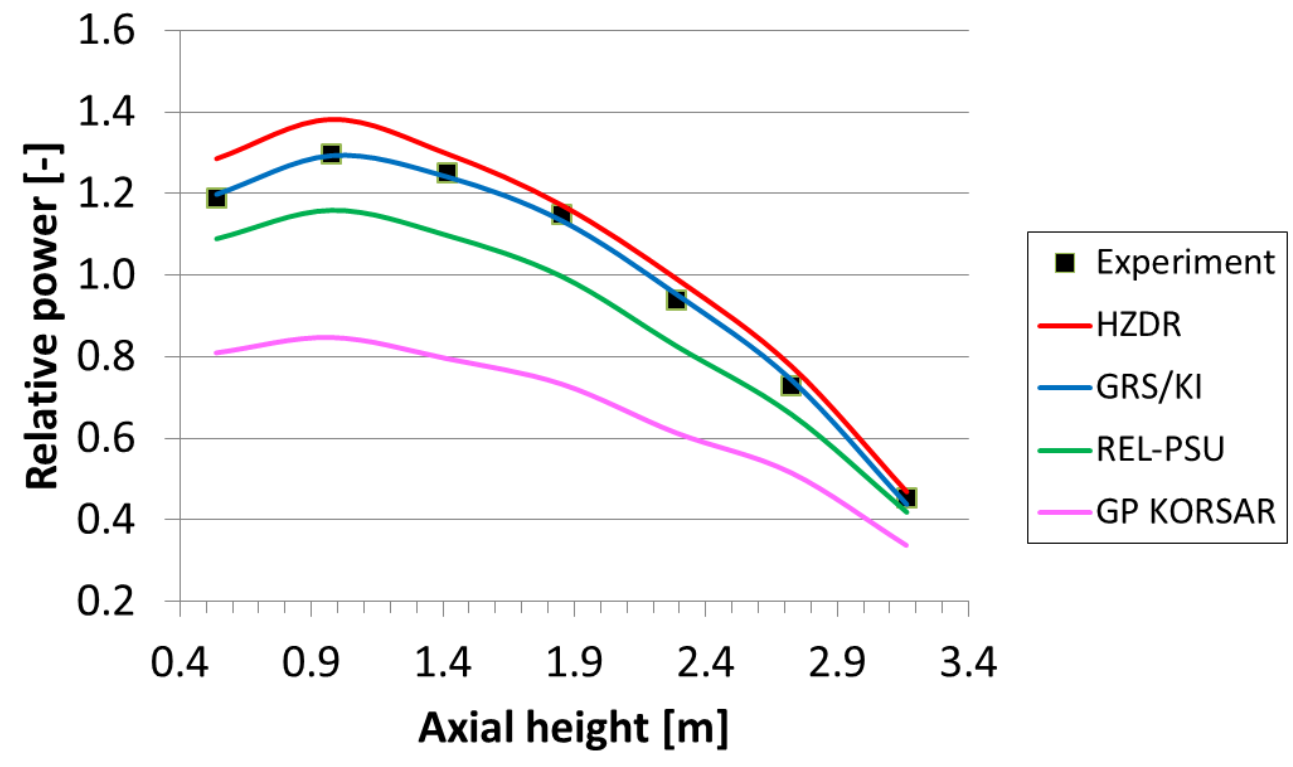

Figure 20. Snapshot of relative axial nodal power at $\mathrm{SFA \# 10}$ at $\mathrm{t}=45 \mathrm{~s}$ 


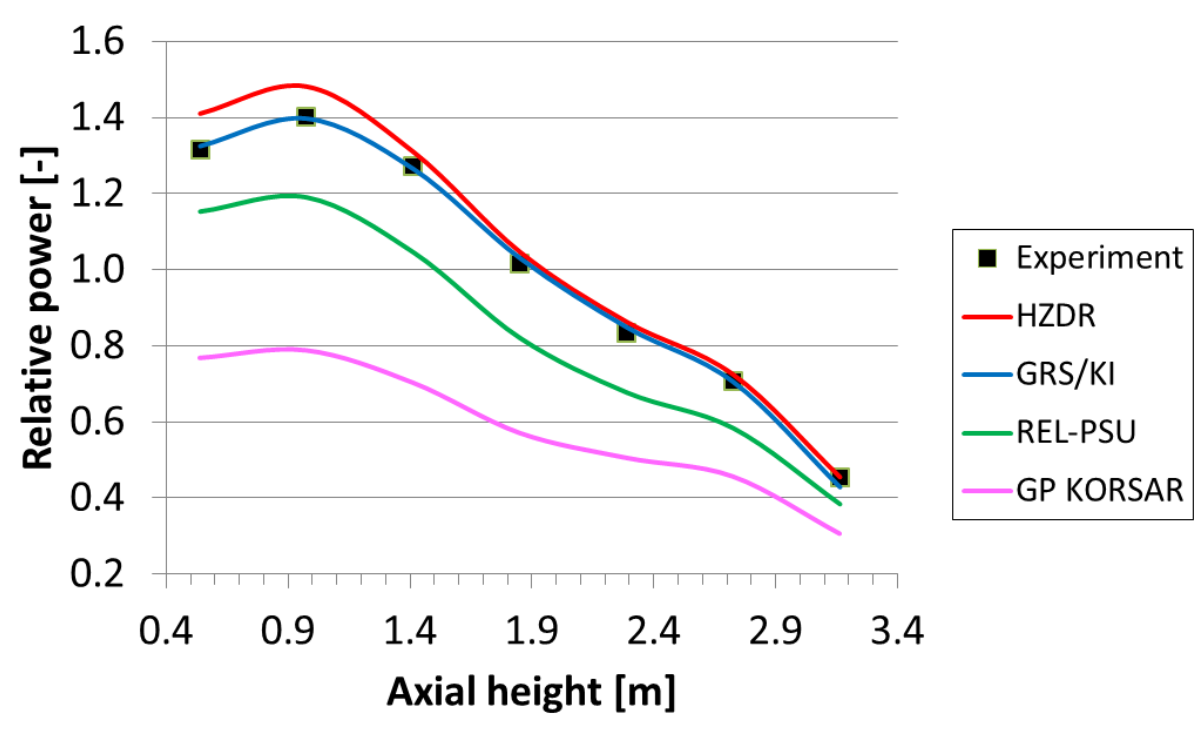

Figure 21. Snapshot of relative axial nodal power at $\mathrm{SFA \# 10}$ at $\mathrm{t}=300 \mathrm{~s}$

\section{OECD/NRC Oskarshamn-2 BWR Stability Benchmark}

\subsection{Objectives}

The previous OECD benchmarks for the coupled neutronics-thermal/hydraulics codes have confirmed the codes' capability to model and simulate postulated accidents (PAs) and anticipated operational occurrences (AOOs). The primary objective of the Oskarshamn-2 BWR stability benchmark is to establish confidence in extending code applications from its original intended use such as PAs and AOOs, to more challenging events such as unstable power oscillations without scram, where non-linear models are necessary.

The previous BWR stability benchmarks, such as the Peach Bottom 2 stability tests [11], OECD Ringhals 1 [12] and Forsmark [13] benchmarks, are based on noise measurements of a stable reactor, where a decay ratio (DR) less than 1.0 was measured for all conditions. The Osharshamn-2 BWR stability benchmark is the first benchmark based on measured plant data for a stability event with a DR greater than one. This problem is challenging to neutron kinetics (NK), thermal-hydraulics (TH), and TH/NK coupling, where high-fidelity coupled TH/NK is required.

The benchmark is based on the Oskarshamn-2 NPP and the transient measurements of the February 25, 1999 event. A loss of feedwater (FW) pre-heaters and control system logic failure resulted in a condition with a high feedwater flow and low feedwater temperature without reactor scram. In addition to the initiating event, an interaction of the automatic power and flow control system caused the plant to move into a low flow - high power regime. The combination of the above events culminated in diverging power oscillations with in-phase instability, which triggered an automatic scram at high power. The power evolution for the event is shown in Figure 22.

\footnotetext{
* Corresponding author - e-mail: mna109@psu.edu; Tel.: +1-814-865-0043; Fax: +1-814-865-8499
} 


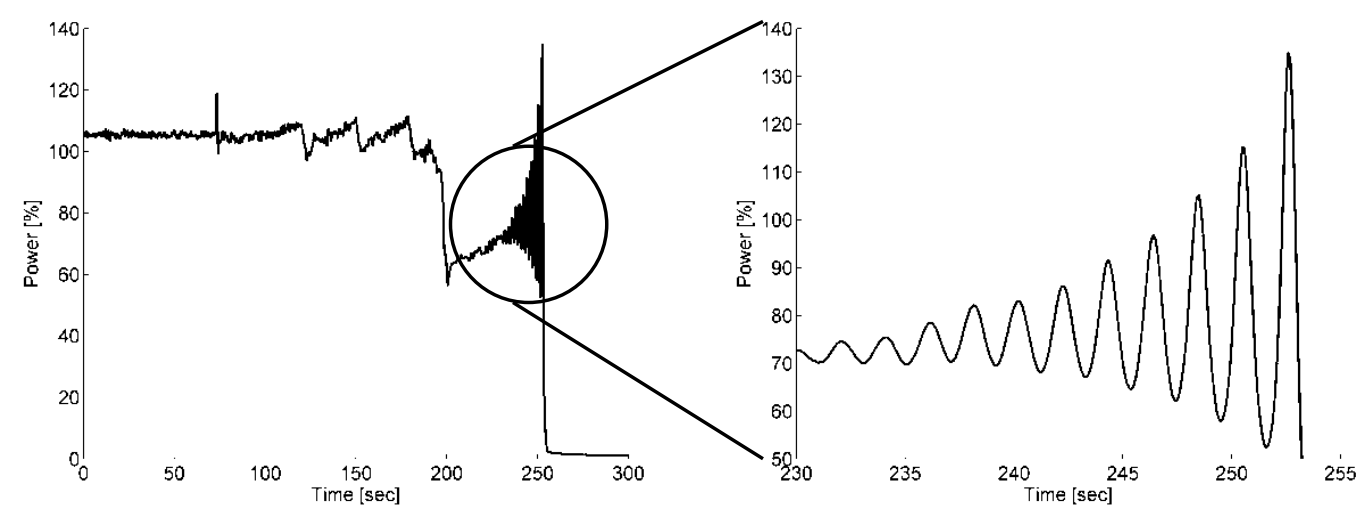

Figure 22. Oskarshamn-2 February 25, 1999 feedwater transient

A full-core, three-dimensional coupled neutronics/thermal-hydraulics model was created using the US NRC coupled code system TRACE (TRAC/RELAP Advanced Computational Engine)/PARCS (Purdue Advanced Reactor Core Simulator). The TRACE/PARCS model has been prepared based on the plant documentation and existing plant models. It consists of explicit core, vessel, recirculation loop, separator, feedwater and steam line models. The balance-of-plant was modeled through controllers and boundary conditions.

The initial and boundary conditions necessary for modeling of the February 1999 feedwater transient (stability event) have been made available by the plant. Time-dependent FW flow and temperature boundary conditions were taken directly from plant data during the event, with the FW temperature corrected due to resistance temperature detectors (RTD) time delay. The steam line outlet pressure was adjusted to match the measured steam dome pressure. Finally, the recirculation pump speed was adjusted to give the correct recirculation flow rate during the event. The pump speed was prescribed in the model, rather than the pump flow rate itself, in order to more accurately represent the recirculation loop dynamics, in which the changing flow resistance in the primary loop during oscillations can create a significant feedback effect on recirculation flow rate.

The core has been modeled in TRACE using 222 core channels, corresponding to half-core symmetry. Axially, the core channels have been divided into 28 axial nodes, with node size proportional to the maximum vapor velocity among all channels (with larger nodes at top of the core) to stay as close as possible to the Courant limit in all cells. As shown in previous stability modeling with TRACE/PARCS $[14,15]$, this procedure helps cancel out the spatial and temporal discretization errors as closely as possible in order to minimize numerical diffusion, which has a strong dampening effect on any oscillations predicted by the codes. A finer meshing at the bottom of the core also has the benefit of a well-resolved boiling height, which is important for the prediction of BWR stability.

The TRACE/PARCS model has been described in detail in previous publication [16]. The complete plant information necessary to create a computational TH/NK model is given in the benchmark specifications [17].

\subsection{Summary of results}

This benchmark is in progress. It is well attended with large number of participants form industry, research institutions, regulatory organizations, and academia. In this paper only preliminary results are presented with TRACE/PARCS. These results are obtained from the benchmark organizers to illustrate the capabilities of current multi-physics codes to simulate BWR instabilities. First, the initial steady-state conditions measured or calculated by the plant were compared with those calculated by TRACE/PARCS.

* Corresponding author - e-mail: mna109@psu.edu; Tel.: +1-814-865-0043; Fax: +1-814-865-8499 
The steady-state conditions calculated by TRACE/PARCS were in excellent agreement with the measured or plant-calculated results. In addition, the model has been validated with two stability measurements performed in December 1998, approximately 3 months before the event. The results have been presented in a previous paper [18].

The TRACE/PARCS transient power is shown on Figure 23. Using the original (as measured) boundary conditions, the instability behavior is predicted qualitatively well, but there is a systematic power deviation since $120 \mathrm{sec}$, well before the onset of instability $220 \mathrm{sec}$. Compensating for the time delay in the FW temperature measured signal, the TRACE/PARCS solution is in an excellent agreement with the plant data, capturing the entire behavior of the transient, including power behavior during pump runback, partial scram, onset of instability, growth of oscillation (decay ratio), oscillation frequency and the scram.

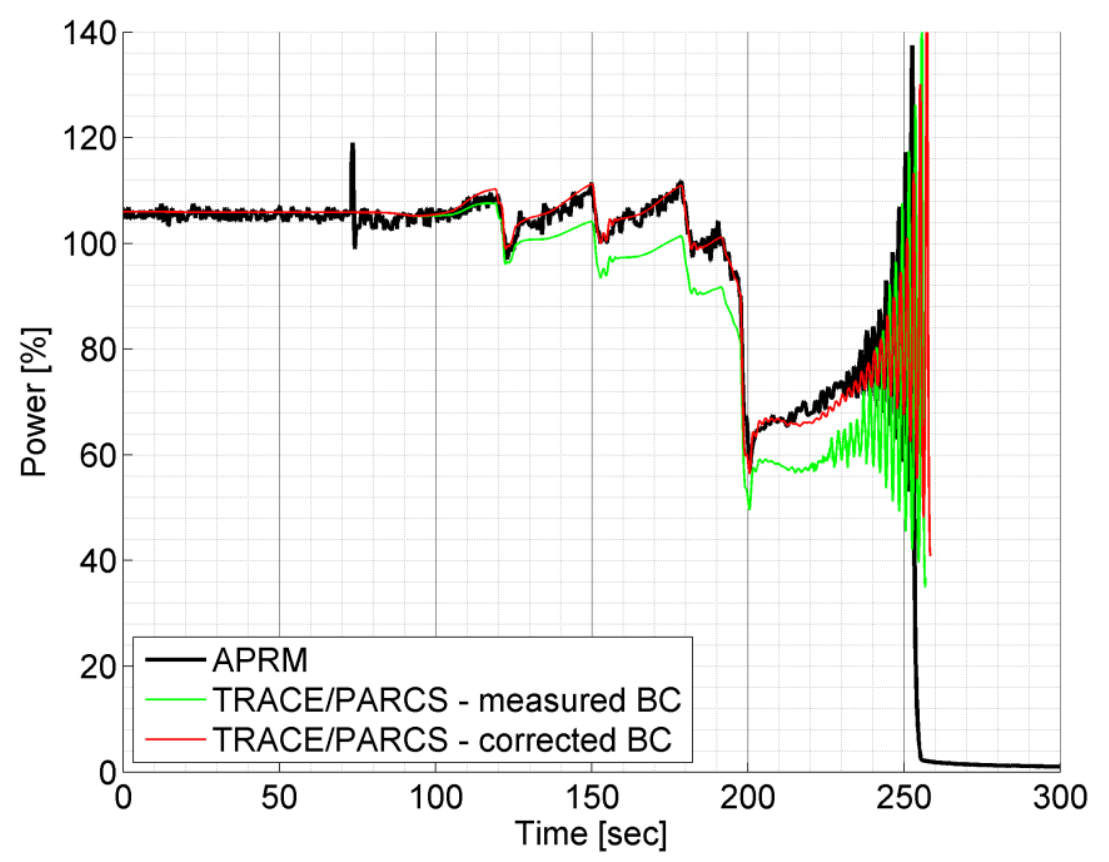

Figure 23. Oskarshamn-2 February 25, 1999 feedwater transient, TRACE/PARCS solution

A TRACE/PARCS model has been developed for the Oskarshamn-2 reactor and validated with the February 1999 steady-state and transient conditions. The event provides coupled code validation for a challenging BWR stability event, which involves the accurate simulation of neutron kinetics (NK), thermal-hydraulics (TH), and TH/NK coupling. The success of this work has demonstrated the ability of 3-D coupled system code TRACE/PARCS to capture the complex behavior of BWR stability event with a decay ratio larger than unity, and provides confidence in the prediction of other parameters which are not available from the plant records. The problem was released as an international OECD/NEA benchmark, and it is the first benchmark based on measured plant data for a stability event with a DR greater than one.

\section{OECD Benchmark for Uncertainty Analysis in Modelling (UAM) for the Design, Operation and Safety Analysis of LWRs (UAM-LWR)}

\subsection{Objectives}

Design and safety studies are now based on best-estimate approach rather than conservative. Hence, multi-physics computation has been developed for about two decades in order to improve the confidence

* Corresponding author - e-mail: mna109@psu.edu; Tel.: +1-814-865-0043; Fax: +1-814-865-8499 
and the quality of numerical simulation of nuclear reactors. Nevertheless best-estimate calculations need to be supported by Sensitivity and Uncertainty Analysis (SA/UA). This is particularly important when coupling effects are considered, with possible opposite trends on safety parameters. Expert judgment might be limited and has to be replaced by a comprehensive sensitivity and uncertainty study.

Based on this statement, the expert groups who have been involved in the previous OECD/NEA benchmarks (see other Sections in the paper) decided in 2006 to launch a new project, aimed at introducing SA/UA in coupled calculations.

The first objective of UAM-LWR is to share experience and feedback about SA/UA among the benchmark participants. In practice, two stages are necessary: i) to identify the relevant techniques for multi-physics and coupled calculations; ii) to provide a comprehensive and consistent approach for uncertainty evaluation from nuclear data to full plant accidental transients. The first objective is already achieved by the UAM benchmark: improving the state-of-the-art in best-estimate plus uncertainty (BEPU) calculations. Most of participants started with a limited experience in SA/UA, particularly in coupled calculations. Furthermore there was no such comprehensive approach for uncertainty propagation from fuel cell physics to reactor transient analysis.

The UAM-LWR benchmark covers three main topics of nuclear engineering: neutronics, thermalhydraulics and fuel thermal and mechanical behavior, and addresses the main types of LWRs: PWR (including Gen III), BWR and VVER.

As for previous benchmarks, a step-by-step approach is necessary to be able to analyze the results obtained by the participants. A total of ten steps, organized in three phases, are defined:

- Phase I: stand-alone neutronics

- Exercise I-1: cell physics. This exercise addresses the derivation of multi-group cross-section libraries with neutron transport codes.

- Exercise I-2: lattice physics. This exercise focuses on the derivation of few-group homogenized parameters such as cross-sections, Assembly Discontinuity Factors.

- Exercise I-3: core physics. Three-dimensional core calculations are considered with fixed boundary conditions for feedback parameters (e.g. fuel temperature).

- Phase II: core models without coupling

- Exercise II-1: fuel physics. This exercise deals with fuel thermal properties relevant for steady-state and transient.

- Exercise II-2: time-dependent neutronics. This exercise addresses both fuel depletion and kinetics (fast transients).

- Exercise II-3: fuel bundle thermal-hydraulics. This exercises focuses on stand-alone fuel assembly calculations.

- Phase III: coupling and system

- Exercise III-1: core. This exercise couples neutronics and thermal-hydraulics models with fixed core boundary conditions (e.g. core inlet temperature).

- Exercise III-2: system. This exercise addresses the full plant thermal-hydraulics behavior in steady-state and transient.

- Exercise III-3: core-system. This exercise couples the neutronics/thermal-hydraulics core and the thermal-hydraulics system models.

* Corresponding author - e-mail: mna109@psu.edu; Tel.: +1-814-865-0043; Fax: +1-814-865-8499 
- Exercise III-4: conclusion. Best-estimate plus uncertainty (BEPU) approach is compared to conservative calculations.

For each exercise, several test problems are considered in order to cover the different situation targets: reactor types, normal operation conditions and accidental transients. The benchmark specifications are designed to allow a partial participation. For instance, some participants may be interested in BWR situations only, or in one step only (e.g. fuel physics).

An important task in the benchmark development is the definition and the identification of the uncertainties. Three types of uncertainties are considered for each step or exercise:

- input uncertainties, related mainly to input data,

- output uncertainties, related to the output parameters of the calculations,

- propagated uncertainties, from one step to others.

There are two main sources of uncertainty: data on one hand (e.g. microscopic cross-section, fuel pin diameter) and numerical and physical models on the other hand. Obviously one has to limit the number of uncertain parameters for feasibility: number and complexity of the calculations, analysis and comparison of the results.

As an example, one can list the uncertainties for Exercise II-1:

- input: fuel geometrical and technological data, thermal-hydraulics and thermal power boundary conditions,

- output: fuel temperature and pressure (cf. fission gas release), fuel expansion, pellet and cladding thermal properties (conductivity in particular),

- propagated: fuel temperature, as a feedback parameter for homogenized cross-sections.

Uncertainties are characterized by their distribution type (e.g. normal, uniform) and quantitative parameters (e.g. lower/upper bound, standard deviation).

The benchmark is designed to validate the models as much as possible by comparing the computations with actual data (experiments and measurements). Unfortunately, this is not always possible due to a lack of data (quantity and quality). To overcome this limitation, numerical test problems are specified in addition to experimental test cases.

The second main constraint in the benchmark is the consistency between the different steps and levels of modeling: fuel cell, fuel assembly, and core, reactor (primary and secondary circuit). For that purpose, three reference reactors are chosen, for which data availability is ensured: Three Mile Island Unit 1 for PWR, Peach Bottom Unit 2 for BWR, and Kozloduy Unit 6 for VVER-1000.

Currently Phase I is completed, Phase II is on-going and scheduled to be completed in 2015, and Phase III is in preparation. There is still a significant amount of work before reaching the final goal, i.e. assessing the gain for safety and design studies between BEPU and classical conservative methods.

\subsection{Summary of results}

\subsubsection{Phase I-stand-alone neutronics}

A summary of selected results for Phase I are shown below. Every participant that has submitted results for Phase I of the LWR-UAM benchmark is listed in Table 8 along with their country and participant code. The uncertainty quantification methodologies, the covariance cross-section libraries and computer

* Corresponding author - e-mail: mna109@psu.edu; Tel.: +1-814-865-0043; Fax: +1-814-865-8499 
codes utilized by the participants were discussed in detail in the special issue entitled "Uncertainty Analysis in Reactor Physics Modeling" published in the Hindawi Publishing Corporation Science and Technology of Nuclear Installations in 2013. For comparative analyses the results of each test case were averaged over all participant-submitted values and are displayed in this section along with the corresponding relative standard deviation (RSD).

Table 8. LWR-UAM benchmark Phase I participants

\begin{tabular}{c|l|c}
\hline $\begin{array}{c}\text { Participant } \\
\text { Code }\end{array}$ & \multicolumn{1}{|c}{ Institution } & Country \\
\hline CEA & $\begin{array}{l}\text { Commissariat à l'énergie atomique et aux énergies } \\
\text { alternatives } \\
\text { CUT }\end{array}$ & France \\
EK & Hungarian Academy of Sciences & Sweden \\
GRS & Gesellschaft für Anlagen- und Reaktorsicherheit & Hungary \\
HU & Hacettepe University & Germany \\
IJS & Jožef Stefan Institute & Turkey \\
JNES & Japan Nuclear Energy Safety Organization & Slovenia \\
KIT & Karlsruhe Institute of Technology & Japan \\
MMU & McMaster University & Germany \\
NRG & Nuclear Research and Consultancy Group & Canada \\
ORNL & Oak Ridge National Laboratory & The Netherlands \\
PSI & Paul Scherrer Institut & USA \\
PSU & The Pennsylvania State University & Switzerland \\
SNU & Seoul National University & USA \\
UM & University of Michigan & South Korea \\
UP & University of Pisa & USA \\
UPC & Universitat Politècnica de Catalunya & Italy \\
UPM & Universidad Politécnica de Madrid & Spain \\
VTT & VTT Technical Research Centre & Spain \\
\hline
\end{tabular}

For example, for Exercise I-3 for each of the four reactor core test cases (PB-2, TMI-1, Kozloduy-6, and GEN-III UOX and MOX) one of the requested output that was submitted by participants was $\mathrm{k}_{\text {eff. }}$ These participant-averaged values of $\mathrm{k}_{\mathrm{eff}}$ are summarized in Table 9 for each test case.

The obtained results from sensitivity and uncertainty analysis for the test cases of Exercises I-1 and I-2 indicated that the largest contributors to prediction uncertainties of infinite multiplication factor are the neutron capture reaction ${ }^{238} \mathrm{U}(\mathrm{n}, \gamma)$ and corresponding cross-section (for UOX fuel) and ${ }^{238} \mathrm{U}$ (n, n') reaction and corresponding cross-section (for MOX fuel and UOX fuel with $\mathrm{Gd}_{2} \mathrm{O}_{3}$ burnable poison). When depletion is involved for UOX fuel the major contributor ${ }^{238} \mathrm{U}(\mathrm{n}, \gamma)$ is replaced by ${ }^{239} \mathrm{Pu}$ nubar (average number of neutrons per fission reactions - v) as the burnup process progresses (at approximately $15 \mathrm{GWd} / \mathrm{MTU}$ ) and ${ }^{239} \mathrm{Pu}$ content increases.

* Corresponding author - e-mail: mna109@psu.edu; Tel.: +1-814-865-0043; Fax: +1-814-865-8499 
New methods have been developed and implemented to work with existing reactor physics computer codes during benchmark activities related to Phase I of the OECD/NEA UAM-LWR benchmark. One of the outcomes was the finding that the propagation of cross-section uncertainties, uncertainties of depletion and kinetics parameters, and manufacturing uncertainties in core calculations can be done in a practical manner by combining deterministic and statistical uncertainty and sensitivity methodologies.

Table 9. Participant-averaged $\mathbf{k}_{\text {eff }}$ values for each submitted case

\begin{tabular}{l|c|c|c}
\hline \multicolumn{1}{c|}{ Case } & Condition & Value & RSD (\%) \\
\hline PB-2 & HZP & 0.9781 & 0.548 \\
TMI-1 & HZP & 1.3019 & 0.454 \\
KOZ-6 & HZP & 1.0010 & 0.555 \\
GEN-III MOX & HFP & 1.0051 & 0.551 \\
GEN-III UOX & HFP & 1.0055 & 0.593 \\
\hline
\end{tabular}

As an example of new developed capability is the XSUSA system with which GRS has been participating in the UAM-LWR benchmark and contributed results to many of the exercises of Phase I of this benchmark. The code system XSUSA ("Cross Section Uncertainty and Sensitivity Analysis") [20] is being developed for performing sampling-based uncertainty and sensitivity analysis with respect to nuclear data. Basically, many calculations of the problem under consideration are being performed with varied nuclear data. The variations are generated randomly from the given probability distribution functions including correlations. This information is available in so-called covariance matrices. After performing the whole series of calculations, output quantities of interest are statistically analyzed, and their uncertainty intervals as well as sensitivity indicators with respect to input parameters can be determined. As application code system for the nuclear calculations, the Modelling and Simulation Suite for Nuclear Safety Analysis and Design SCALE 6.1 [21] is being used. It contains a nuclear data library based on ENDF/B-VII along with the corresponding covariance data in multi-group structure, and code sequences for resonance self-shielding, deterministic and Monte Carlo neutron transport, and depletion calculations. Also, few-group data can be generated for subsequent core simulations with, e.g., the GRS code system QUABOX/CUBBOX-ATHLET.

In Figure 24, results from calculations for a LEU pin cell performed within Phase I of the UAM-LWR benchmark [10] are displayed. The figure shows the $1 \sigma$ uncertainties of the multiplication factor $\left(\mathrm{k}_{\mathrm{eff}}\right)$ and one-group cross sections $($ abs $=$ absorption, fis $=$ fission) obtained with XSUSA in comparison with corresponding results obtained with the generalized perturbation theory capability of the SCALE 6.1 module TSUNAMI. The neutron transport solver underlying both the TSUNAMI and XSUSA analyses is the $\mathrm{S}_{\mathrm{N}}$ code XSDRN from the SCALE 6.1 system; to apply this one-dimensional code, the pin cells are represented as cylinders with equivalent areas. For the XSUSA random sampling analysis, 1,000 calculation runs were evaluated. The uncertainties resulting from both methods generally agree very well, with a maximum relative difference below $5 \%$ (for the U-234 absorption cross-section); here, it has to be noted that for a sample size of 1000 , the relative $95 \%$ confidence interval for $\sigma$ is $[-4.1 \%,+4.7 \%]$.

Figure 25 shows the pin fission rate distribution across the KRITZ-2:13 core, which has also been investigated in the framework of UAM-LWR Phase I. KRITZ-2:13 is a light-water moderated square lattice of 40x40 LEU pins. A detailed description [22] can be found in the International Handbook of Evaluated Reactor Physics Benchmark Experiments. While a substantial uncertainty is found for the multiplication factor (TSUNAMI-3D: $0.537 \%$, XSUSA/KENO: $0.527 \%$ ), which exceeds the evaluated measurement uncertainty of approximately $0.21 \%$, the nuclear data uncertainties have no significant

* Corresponding author - e-mail: mna109@psu.edu; Tel.: +1-814-865-0043; Fax: +1-814-865-8499 
influence in the central part of the core. The uncertainty band is indicated by the dashed lines. Only at the core boundary, where the fission rates are low anyway, they cause uncertainties in the fission rate distribution in the order of $1 \%$. It is seen that the measurement uncertainties give a larger contribution to the overall uncertainty. Again, 1,000 calculation runs were evaluated for the XSUSA analysis.

As examples of uncertainties in full-core calculations, two Generation-III PWR core designs specified in Ref. [10] have been chosen, one with a $\mathrm{UO}_{2}$ loading, and one with a mixed $\mathrm{MOX} / \mathrm{UO}_{2}$ loading where the assemblies at the core periphery contain MOX fuel. After generating self-shielded cross-sections for all fuel assemblies, the core calculations were performed with the Monte Carlo code KENO-Va from the SCALE 6.1 code system. The results for the relative uncertainties in the radial power distributions from 300 calculations are given in Figure 26. In particular for the mixed core, the uncertainties in the core center and at the periphery are substantial, with values exceeding $10 \%$. The major contributor for these uncertainties are the uncertainties plutonium $(\mathrm{Pu}-239)$ fission yield (nu-bar). These large uncertainties in the power distribution predicted for the MOX core caused by cross section uncertainties are not consistent with the difference between prediction and measurement observed for MOX cores. This fact indicates that most probably there is a cancelation/compensation of cross-section uncertainties with other sources of uncertainties, which were not investigated in this study.

\subsubsection{Phase II - core models without coupling}

Finally, as the first contributions to Phase II of the LWR-UAM benchmark [19], results of the uncertainty and sensitivity analysis for the depletion calculation of a PWR fuel assembly are presented. Please note that this is a single solution and that further solutions will need to be evaluated before drawing any conclusions. The depletion calculations were performed with a 2-dimensional representation of the fuel assembly; the SCALE 6.1 burn-up sequence TRITON was used, with the deterministic $S_{N}$ code NEWT as transport solver. To save CPU time, the basic 238 group ENDF/B-VII cross-section library was precollapsed to 44 energy groups with a representative LWR neutron spectrum. Again, series of 1,000 runs were performed. The calculated multiplication factor as a function of the burn-up is displayed in Figure 27 , along with its $1 \sigma$ uncertainty. For fresh fuel, the relative $1 \sigma$ uncertainty is $0.49 \%$; this is typical for light water moderated low-enrichment uranium pin cell lattices. With increasing burn-up, the uncertainty significantly increases. This is mainly due to the fact that the fuel assemblies change from pure LEU systems at the beginning of life to MOX systems at the end of life. Earlier observations of LEU and MOX systems with XSUSA and TSUNAMI have consistently shown that the main contributions to the $\mathrm{k}_{\text {eff }}$ uncertainty come from the uncertainty in the U-238 capture cross-section for LEU, and the Pu-239 nu-bar uncertainty for MOX. The corresponding squared multiple correlation coefficients, used as uncertainty importance indicators, are shown in Figure 28, along with their 95\% confidence interval and their 95\% significance bound. It can in fact be seen that for fresh fuel, the main contributor is the U-238 capture cross-section uncertainty; in the course of burn-up, it decreases and the Pu-239 nu-bar uncertainty becomes the most important contributor.

As illustration of expected analysis for Exercise II-3, results are provided below based on the uncertainty and sensitivity analysis performed using the GRS' SUSA code (Software for Uncertainty and Sensitivity Analysis) and the PSU's advanced version of the thermal-hydraulic sub-channel code COBRA-TF [23]. The presented solution is only given for illustrative purposes and that more definitive conclusions will only be drawn once other solutions have been evaluated. The uncertainties propagated in this study are boundary condition uncertainties, geometrical uncertainties, and modelling parameter uncertainties. For all cases, the prediction uncertainty regarding the coolant, fuel and cladding temperature is low. The absolute uncertainty of the void fraction is low and approximately the same for all cases. Therefore, the relative uncertainty increases when the void fraction decreases. The results show the dominating sources of uncertainty for each case through the correlation rank coefficients. The geometrical uncertainties can be neglected compared to the boundary condition and modelling uncertainties.

* Corresponding author - e-mail: mna109@psu.edu; Tel.: +1-814-865-0043; Fax: +1-814-865-8499 
The GRS' SUSA code also includes tools for sensitivity analysis. These can measure the importance of parameter uncertainties for the uncertainties of the results. SUSA features several sensitivity indicators such as: standardized rank regression coefficients, rank correlation coefficients (abbreviated as RCC) or correlation ratios. The Spearman's RCC is selected as sensitivity indicator for the present study. The RCC for a variable $\mathrm{Y}$ with respect to an uncertain parameter $\mathrm{X}$ has the following properties:

1) $\quad-1 \leq \mathrm{RCC} \leq+1$

2) if the result variable $\mathrm{Y}$ is independent of parameter $\mathrm{X}$, then $\mathrm{RCC}=0$

3) if the result variable $\mathrm{Y}$ is a monotone increasing function of $\mathrm{X}$, then $\mathrm{RCC}=+1$

4) if the result variable $\mathrm{Y}$ is a monotone decreasing function of $\mathrm{X}$, then $\mathrm{RCC}=-1$

The determination coefficient of the Spearman's correlation matrix $\left(\mathrm{R}^{2}\right)$ is an important parameter. Indeed, $\mathrm{R}^{2}$ represents the share of output uncertainty that can be explained by the uncertain input parameters. Thus, if all the output variations can be correlated to the input variations, then $\mathrm{R}^{2}=1.0$.

As an example the obtained results for the steady-state BWR case based on PB-2 bundle (see Figure 29) are summarized in Table 10. The determination coefficient $\mathrm{R}^{2}$ is close to 1.0 for all output parameters. Therefore, the analysis of the RCCs is relevant. The main uncertainty contributors to the void fraction around the corner rod can be seen in Figure 30. The inlet enthalpy has the highest Spearman's RCC (values around 0.7 ). It has a positive contribution since when the enthalpy increases, the boiling margin decreases.

The next main contributors are modelling parameters: the interfacial drag coefficient for bubbly flow and for film flow. The importance of these parameters is lower in the South-East (SE) channel. Instead, the single-phase mixing coefficient plays a more important role: $\mathrm{RCC} \approx-0.35$ and rank $\# 2$. The pressure has a negative influence on the void fraction $(\mathrm{RCC} \approx-0.29)$. When the pressure increases, the saturation temperature increases and the void fraction decreases.

* Corresponding author - e-mail: mna109@psu.edu; Tel.: +1-814-865-0043; Fax: +1-814-865-8499 


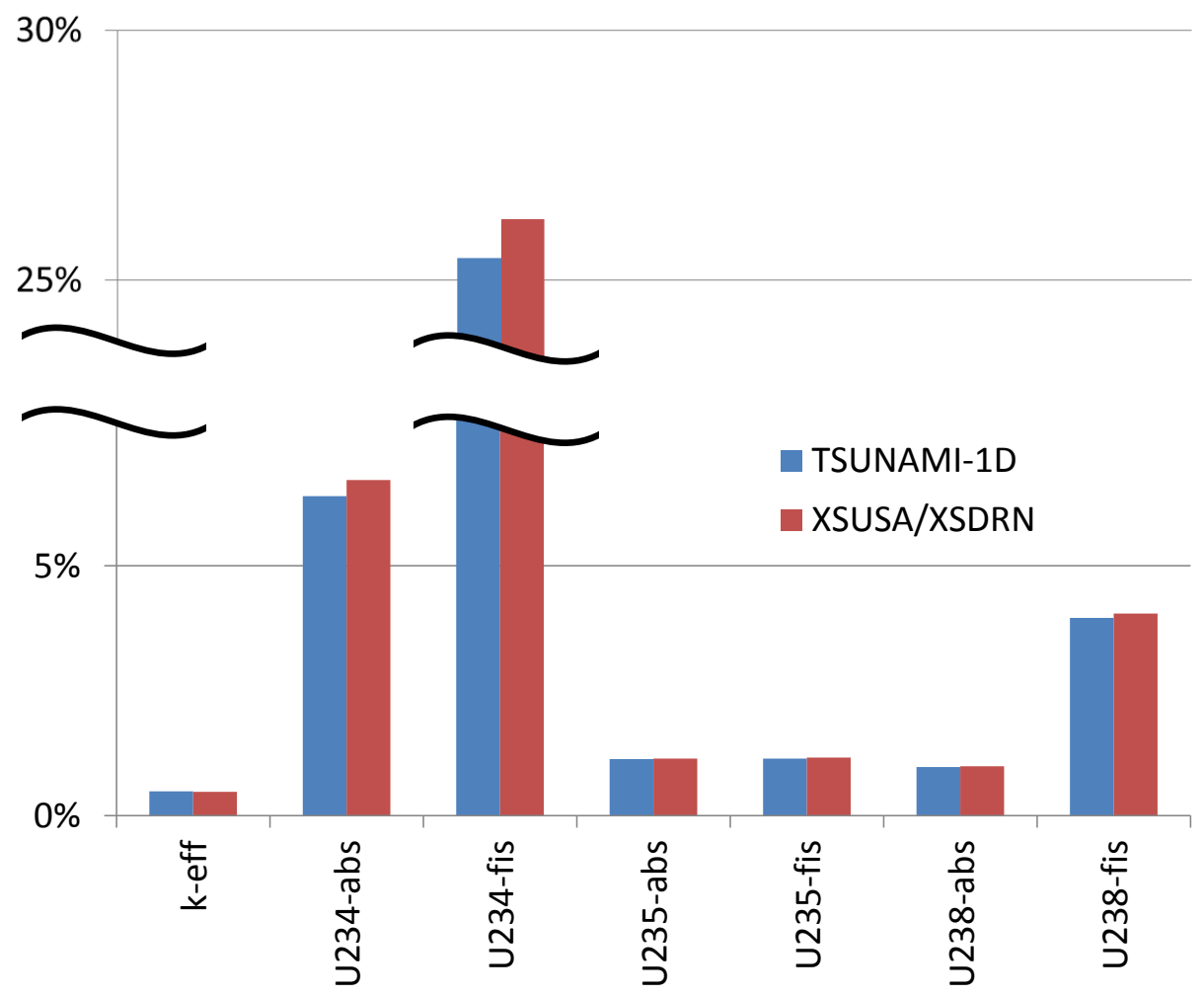

Figure 24. Uncertainties in the multiplication factor and one-group microscopic cross sections for a TMI-1 pin cell, obtained from XSUSA/XSDRN and TSUNAMI-1D calculations.

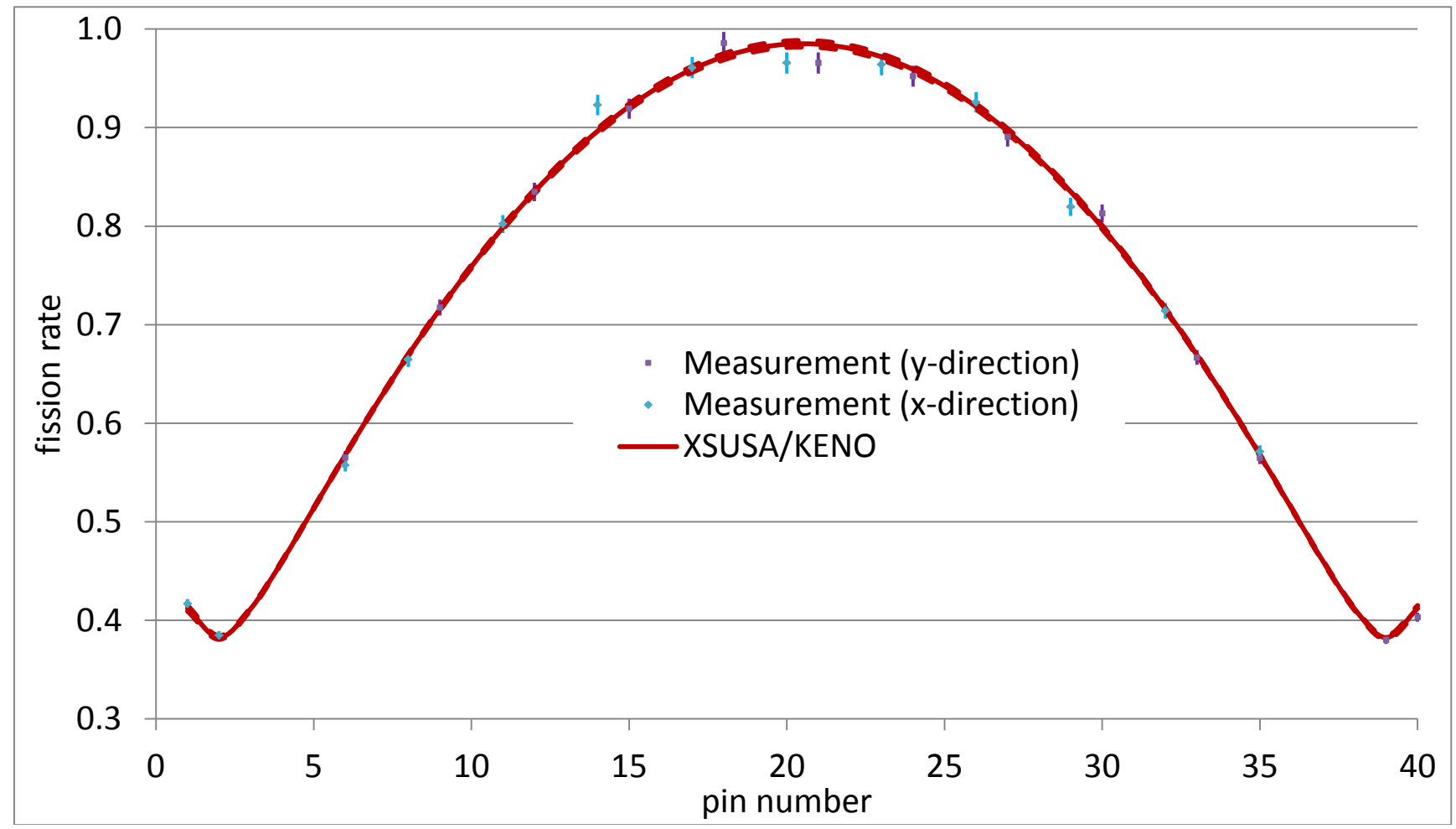

Figure 25. Fission rates and their uncertainty band, obtained from XSUSA/KENO calculations, for the KRITZ-2:13 assembly along with measured values and their uncertainties.

* Corresponding author - e-mail: mna109@psu.edu; Tel.: +1-814-865-0043; Fax: +1-814-865-8499 

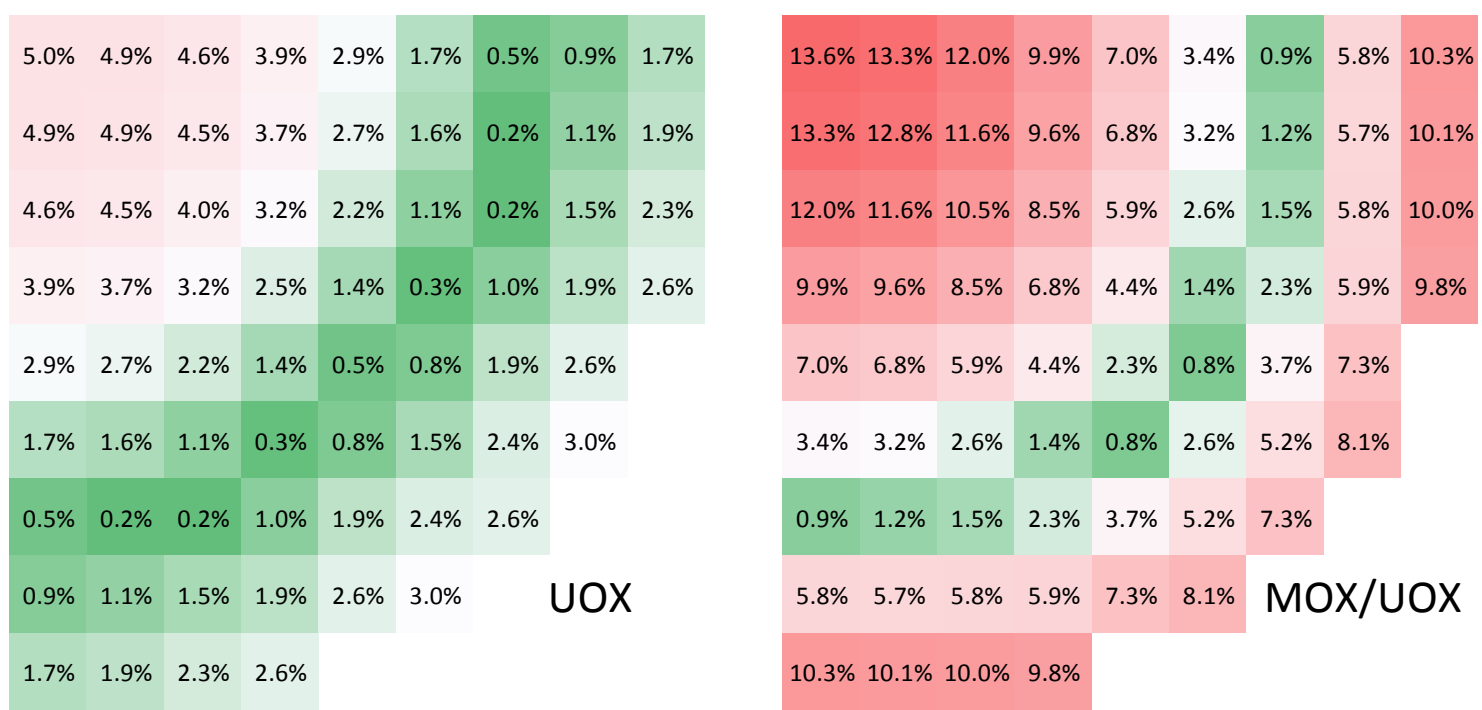

Figure 26. Uncertainties in the power distributions two GEN-III cores designs obtained from XSUSA/KENO calculations.

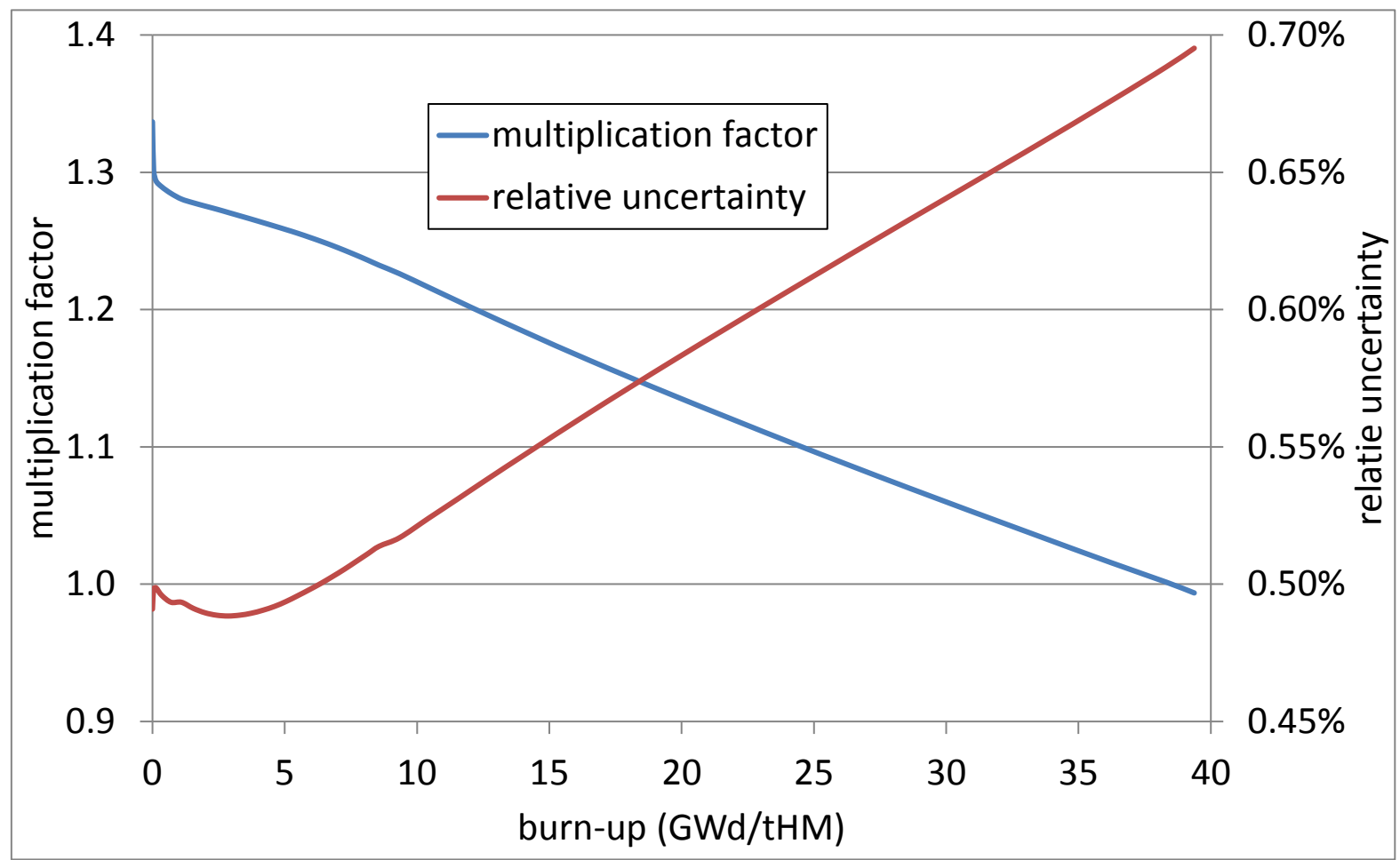

Figure 27. Multiplication factors as a function of burn-up for the PWR fuel assembly and the corresponding $1 \sigma$ uncertainty, obtained from XSUSA/TRITON calculations. 


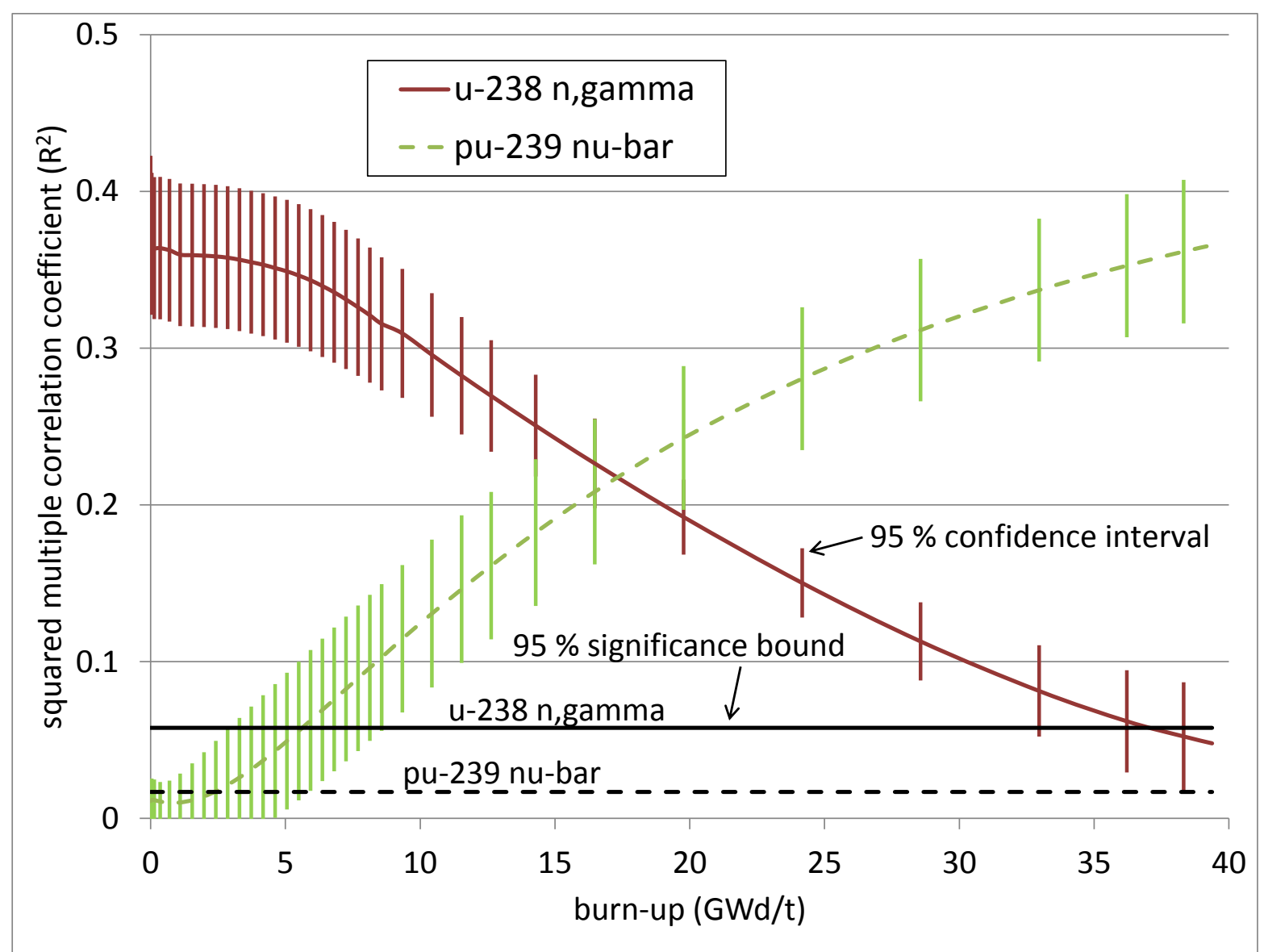

Figure 28. Multiplication factor importance indicators as a function of burn-up for the PWR fuel assembly with $95 \%$ confidence intervals and $95 \%$ significance bounds, obtained from XSUSA/TRITON calculations.

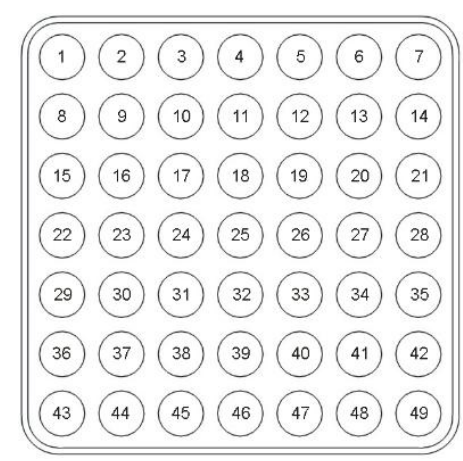

Figure 29. PB-2 bundle image

Table10. Uncertainty Analysis results for PB-2 BWR Steady-State Case - Preliminary Results based on COBRA-TF/SUSA Solution only

\begin{tabular}{|l|c|c|c|c||}
\hline \multicolumn{1}{|c|}{ Parameter } & Reference & Mean Value & $\begin{array}{c}\text { Standard } \\
\text { Deviation }\end{array}$ & $\mathbf{R}^{\mathbf{2}}$ \\
\hline Maximum Fuel Temperature & $1635.9^{\circ} \mathrm{C}$ & $1642.6^{\circ} \mathrm{C}$ & $19.7^{\circ} \mathrm{C}(1.2 \%)$ & 0.9441 \\
\hline Maximum Cladding & $333.3^{\circ} \mathrm{C}$ & $333.6^{\circ} \mathrm{C}$ & $0.97{ }^{\circ} \mathrm{C}(0.3 \%)$ & 0.9917 \\
\hline
\end{tabular}

* Corresponding author - e-mail: mna109@psu.edu; Tel.: +1-814-865-0043; Fax: +1-814-865-8499 


\begin{tabular}{|l|c|c|c|c||}
\hline \hline Temperature & & & & \\
\hline Maximum Void Fraction & 0.693 & 0.694 & $0.007(1.0 \%)$ & 0.9905 \\
\hline Corner Fuel Temperature & $1491.3^{\circ} \mathrm{C}$ & $1496.9^{\circ} \mathrm{C}$ & $21.0{ }^{\circ} \mathrm{C}(1.4 \%)$ & 0.9944 \\
\hline $\begin{array}{l}\text { Corner Cladding } \\
\text { Temperature }\end{array}$ & $330 .{ }^{\circ} \mathrm{C}$ & $330.2^{\circ} \mathrm{C}$ & $0.93{ }^{\circ} \mathrm{C}(0.3 \%)$ & 0.9963 \\
\hline Corner NW Void Fraction & 0.618 & 0.615 & $0.007(1.1 \%)$ & 0.9914 \\
\hline Corner NE Void Fraction & 0.655 & 0.653 & $0.007(1.1 \%)$ & 0.9914 \\
\hline Corner SW Void Fraction & 0.655 & 0.653 & $0.007(1.1 \%)$ & 0.9925 \\
\hline Corner SE Void Fraction & 0.693 & 0.694 & $0.007(1.4 \%)$ & 0.9905 \\
\hline
\end{tabular}

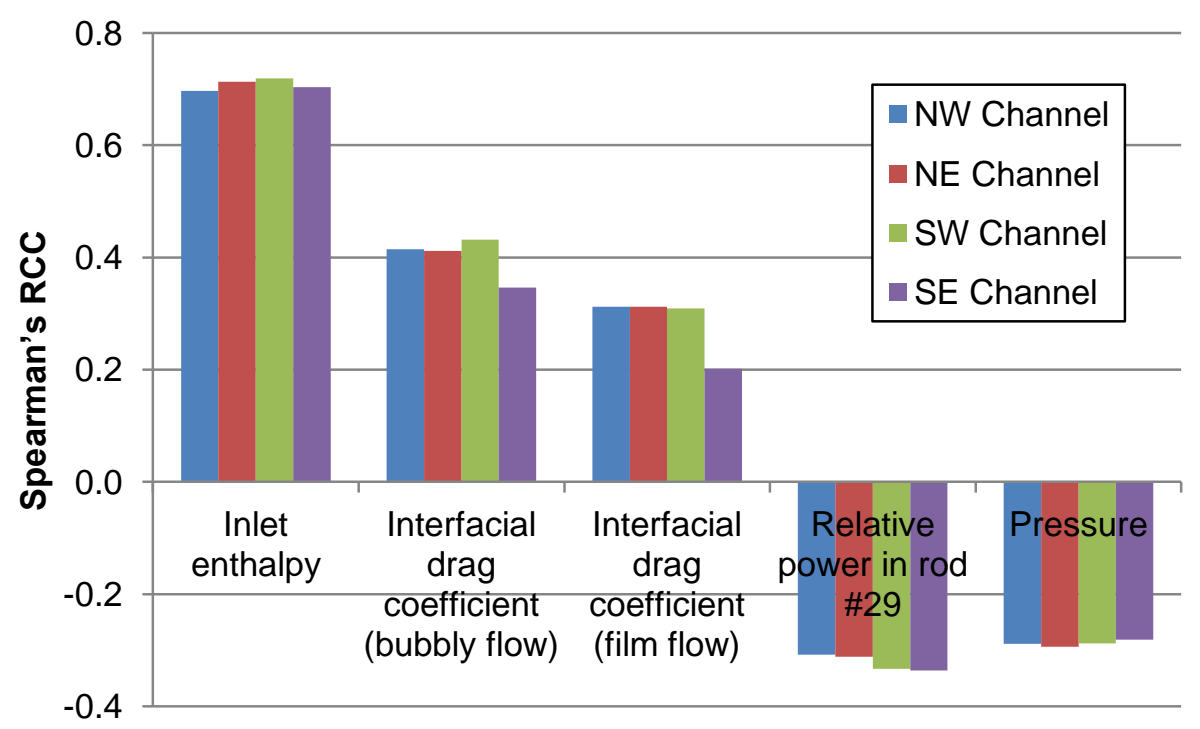

Figure 30. Main uncertainty contributors to the target sub-channel voids of PB-2 BWR SteadyState Case - Preliminary results based on COBRA-TF/SUSA Solution only

\section{Conclusions and Outlook}

It is expected that the application of advanced multi-physics and multi-scale codes for reactor design and safety analyses will be continuously growing. This paper summarizes the second set of NEA/OECD benchmarks, initiated by EGUAM under NSC to address the current trends in the development of LWR multi-physics and multi-scale modelling and simulation. These new benchmarks include the following common features:

a) Utilization of high-quality experimental data;

b) Refined local scale modelling in addition to global predictions;

c) More detailed comparisons and analysis;

d) Including uncertainty and sensitivity analysis of modelling predictions.

The OECD/NRC BFBT benchmark is aimed to reduce the uncertainties in steady-state and transient void distribution and critical power predictions on different scale of thermal-hydraulic simulation tools (system, sub-channel, and CFD codes) using full-scale mock-up experiments for BWR conditions. Similar are the objectives of the OECD/NRC PSBT benchmark but applied to PWR conditions. Both benchmarks have been successfully completed and final reports are being published. Selected cases of BFBT and PSBT benchmarks are integrated in Phase II (Exercise II-3) of the on-going OECD UAMLWR benchmark.

\footnotetext{
* Corresponding author - e-mail: mna109@psu.edu; Tel.: +1-814-865-0043; Fax: +1-814-865-8499
} 
The OECD Kalinin-3 coupled code benchmark is focused on validation of coupled neutronics/thermalhydraulics codes for VVER-1000 design and safety analysis using high-quality multi-physics measured data and performing uncertainty analysis (studying the propagation of uncertainties at different stages of simulation). The last part established interactions with the OECD UAM-LWR benchmark activities. As a result the OECD Kalinin-3 benchmark is merged in Phase III of the UAM-LWR benchmark.

The OECD/NRC Oskarshamn-2 benchmark is designed to validate of coupled codes for BWR instability simulation using plant measured data, to challenge code to the limits of their capability, and to perform uncertainty analysis for code predictions. The propagation of uncertainties at different stages of simulation constitutes interactions with the UAM activity and the OECD/NRC Oskarshamn-2 benchmark will also merge in Phase III of the OECD UAM-LWR benchmark.

The current tendencies in coupled multi-scale multi-physics code developments are towards systematic integration of uncertainty and sensitivity analysis with simulations for design and safety analysis. The OECD UAM-LWR benchmark activity is designed to address current research and development needs for advanced LWR simulations. The key remaining challenge to be addressed by this benchmark is to develop capability for consistent comparison of results plus uncertainties in code predictions with experimental data supplemented with experimental uncertainties. Establishing of comprehensive and internationally accepted OECD UAM-LWR benchmark framework for uncertainty propagation through multi-physics multi-scale calculations in order to compare different uncertainty analysis methods offers the possibility to accelerate also the licensing process when using advanced LWR simulation tools.

\section{Acknowledgements}

The Pennsylvania State University and University of Illinois would like to acknowledge the support of US NRC and US DOE in the development and conductance of the OECD multi-physics benchmarks. Special thanks to CEA-France for supporting the V1000CT benchmark, JNES and METI of Japan for supporting the BFBT and PSBT benchmarks, and to the Swedish Radiation Safety Authority (SSM) for supporting the Oscarshamn-2 benchmark. The work of GRS is supported by the German Federal Ministry for Economic Affairs and Energy. The contribution of Markus Klein to the UAM-LWR Benchmark is appreciated.

\section{References}

1. Ivanov, K., Sartori, E., Royer, E., Langenbuch, S., Velkov, K., 2007. Validation of Coupled Thermal-Hydraulic and Neutronic Codes for Safety Analysis by International Cooperation. Nuclear Technology, Vol. 157, No. 2, pp. 177-195.

2. Neykov, B., et al., 2006. NUPEC BWR Full-size Fine-mesh Bundle Test (BFBT) Benchmark, Volume I: Specifications. OECD 2006, NEA No. 6212, NEA/NSC/DOC (2005)5, ISBN 92-6401088-2.

3. Aydogan, F., et al., 2010. NUPEC BWR Full-size Fine-mesh Bundle Test (BFBT) Benchmark, Volume II: Uncertainty and Sensitivity Analyses - Specification. OECD 2010, NEA No. 6343, NEA/NSC/DOC (2007)21, ISBN 978-92-64-99124-8.

4. Avramova, M., Ivanov, K., Hochreiter, L., 2007. Analysis of Steady State and Transient Void Distribution Predictions for Phase I of the OECD/NRC BFBT Benchmark Using CTF/NEM. The 12th International Topical Meeting on Nuclear Reactor Thermal Hydraulics (NURETH-12), Paper Number: 140, Sheraton Station Square, Pittsburgh, Pennsylvania, U.S.A. September 30-October 4.

\footnotetext{
* Corresponding author - e-mail: mna109@psu.edu; Tel.: +1-814-865-0043; Fax: +1-814-865-8499
} 
5. Rubin, A., Avramova, A., et al., 2010. OECD/NRC Benchmark Based on NUPEC PWR Subchannel and Bundle Tests (PSBT). Volume I: Experimental Database and Final Problem Specifications. NEA/NSC/DOC (2010)1, January.

6. RDFMG, 2013. CTF - A Thermal-Hydraulic Subchannel Code for LWRs Transient Analyses. User's Manual. Technical Report, The Pennsylvania State University.

7. Office of Nuclear Regulatory Research, 2009. TRACE V5.0 Theory Manual. Field Equations, Solution Methods, and Physical Models. USNRC, Washington DC.

8. Ivanov, B., et al., 2002. VVER-1000 Coolant Transient Benchmark, PHASE 1 (V1000CT-1), Vol. I: Main Coolant Pump (MCP) Switching On - Final Specifications. NEA/NSC/DOC (2002) 6.

9. Tereshonok, V., et al., 2008. Description of a Transient Caused by the Switching-off of One of the Four Operating MCP at Nominal Reactor Power at NPP Kalinin Unit 3, NEA/OECD, July.

10. Ivanov, K., Avramova, M., Kamerow, S., Kodeli, I., Sartori, E., Ivanov, E., Cabellos, O., 2013. Benchmark for Uncertainty Analysis in Modelling (UAM) for the Design, Operation and Safety Analysis of LWRs Volume I: Specification and Support Data for Neutronics Cases (Phase I). NEA/NSC/DOC(2013)7, Nuclear Energy Agency.

11. Carmichael, L., Niemi, R., 1978. Transient and Stability Tests at Peach Bottom Atomic Power Station Unit 2 at End of Cycle 2", EPRI NP-564, June.

12. Lefvert, T., 1994. BWR Stability Benchmark - Final Specifications. NEA/NSC/DOC (94)15.

13. Verdu, G., et al., 2001. Forsmark 1 \& 2 Boiling Water Reactor Stability Benchmark, Time Series Analysis Methods for Oscillation during BWR Operation. NEA/NSC/DOC (2001)2.

14. Xu, Y., Downar, T., Walls, R., Ivanov, K., Staudenmeier, J., March-Leuba, J., 2009. Application of TRACE/PARCS to BWR Stability Analysis. Annals of Nuclear Energy, Volume 36.pp. 317-323.

15. Gajev, I., Ma, W., Kozlowski, T., 2013. Space-Time Convergence Analysis on BWR Stability Using TRACE/PARCS. Annals of Nuclear Energy, Volume 51, pp. 295-306.

16. Kozlowski, T., et al., 2014a. Analysis of the OECD/NRC Oskarshamn-2 BWR stability benchmark. Annals of Nuclear Energy, Volume 67.pp. 4-12.

17. Kozlowski, T., et al., 2014b. BWR Stability Event Benchmark based on Oskarshamn-2 1999 Feedwater Transient. Final Draft Specifications, NEA/NSC/DOC.

18. Kozlowski, T., et al., 2011. TRACE/PARCS Validation for BWR Stability Based on OECD/NEA Oskarshamn-2 Benchmark. Proceedings: The 14th International Topical Meeting on Nuclear Reactor Thermal Hydraulics (NURETH-14), , Toronto, Canada.

19. Blyth, T., Avramova, M., Ivanov, K., Royer, E., Sartori, E., Cabellos, O., Feroukhi, H., Ivanov, E., 2013. Benchmark for Uncertainty Analysis in Modeling (UAM) for Design, Operation, and Safety Analysis of LWRs, Volume 2: Specification and Support Data for the Core Cases (Phase II) - Version 2. NEA/NSC/DOC(2013), March.

20. Zwermann, W., Krzykacz-Hausmann, B., Gallner, L., Pautz, A., 2009. Influence of Nuclear Covariance Data on Reactor Core Calculations. Proc. Second International Workshop on Nuclear Data Evaluation for Reactor Applications (WONDER 2009). Cadarache, France, 29 Sep. - 2 Oct., 2009, pp. 99-104.

21. ORNL, 2001. SCALE: A Comprehensive Modeling and Simulation Suite for Nuclear Safety Analysis and Design., ORNL/TM-2005/39, Version 6.1.

22. Snoj, L., Gehin, J., Remec, I., 2006. KRITZ-2:13 Experiment on Regular $\mathrm{H}_{2} \mathrm{O} /$ Fuel Pin Lattices with Low Enriched Uranium Fuel at Temperatures $243{ }^{\circ} \mathrm{C}$. NEA/NSC/DOC (2006)1.

* Corresponding author - e-mail: mna109@psu.edu; Tel.: +1-814-865-0043; Fax: +1-814-865-8499 
23. Périn, Y., Blyth, T., Avramova, M., Velkov, K., 2013. Uncertainty Analysis of COBRA-TF Prediction of Moderator Parameters for the OECD LWR UAM Benchmark, Exercise II-3: Bundle ThermalHydraulics, using the SUSA Tool. Proceedings: The 15th International Topical Meeting on Nuclear Reactor Thermal Hydraulics (NURETH-15), Pisa, Italy, May 12-16.

24. Oberkampf, W., Trucano, T., 2008. Verification and validation benchmarks. Nuclear Engineering and Design. 238, 716-743 